\title{
Inland advance of supraglacial lakes in north-west Greenland under recent climatic warming
}

\author{
Laura A. GLEDHILL, Andrew G. WILLIAMSON \\ Scott Polar Research Institute, University of Cambridge, Cambridge CB2 1ER, UK \\ E-mail: agw41@cam.ac.uk
}

\begin{abstract}
The inland advance of supraglacial lakes (SGLs) towards the interior regions of the Greenland ice sheet (GrIS) may have implications for the water volumes reaching the subglacial drainage system, and could consequently affect long-term ice-sheet dynamics. Here, we investigate changes to the areas, volumes and elevation distributions of over 8000 manually delineated SGLs using 44 Landsat images of a $6200 \mathrm{~km}^{2}$ sector of north-west Greenland over three decades (1985-2016). Our results show that SGLs have advanced to higher maximum $(+418 \mathrm{~m})$ and mean $(+299 \mathrm{~m})$ elevations, and that there has been a near-doubling of total regional SGL areas and volumes over the study period, accelerating after 2000. These changes were primarily caused by an increased SGL area and volume at high $(\geq 1200 \mathrm{~m}$ a.s.l.) elevations, where SGL coverage increased by over $2750 \%$ during the study period. Many of the observed changes, particularly the post-2000 accelerations, were driven by changes to regional surface-temperature anomalies. This study demonstrates the past and accelerating response of the GrIS's hydrological system due to climatic warming, indicating an urgent need to understand whether the increasingly inland SGLs will be capable of hydrofracture in the future, thus determining their potential implications for ice-sheet dynamics.
\end{abstract}

Keywords: Arctic glaciology, climate change, ice and climate, melt - surface, remote sensing

\section{INTRODUCTION AND AIMS}

Given the ongoing and accelerating mass loss from the Greenland ice sheet (GrlS) and thus its contribution to global sea levels (Church and others, 2013; Vaughan and others, 2013; Enderlin and others, 2014), a growing body of research seeks to explore the drivers of this mass loss. Supraglacial lakes (SGLs) traditionally form annually within ice-surface topographic depressions (Echelmeyer and others, 1991) within the GrlS's ablation zone, and are known to influence the loss in three ways. First, due to their lower albedo, SGLs enhance surface melting by 100 $170 \%$ relative to the surrounding bare ice (Lüthje and others, 2006; Tedesco and others, 2012). Second, 13\% of SGLs (Selmes and others, 2011) drain in situ by hydrofracture in as little as $2 \mathrm{~h}$ and commonly in under $24 \mathrm{~h}$. These rapid SGL drainage events deliver huge meltwater pulses to the ice-sheet bed, which can overwhelm the subglacial drainage system, drive down effective pressure, promote ice-bed decoupling and cause transient (hourly-weekly) ice speedups of up to $220 \%$ of background winter velocities (Das and others, 2008; Bartholomew and others, 2010; Banwell and others, 2013, 2016; Doyle and others, 2013; Tedesco and others, 2013). Hydrofracture also creates surface-tobed connections that can receive surface meltwater inputs for the remainder of the melt season, potentially sustaining ice-velocity increases over longer (monthly-seasonal) timescales, notably during any periods of high surface melting (Joughin and others, 2008; Shepherd and others, 2009; Tedstone and others, 2014). Finally, the opening of fractures during rapid SGL drainage results in surface meltwater reaching the colder ice within the ice-sheet body, heating it and thus promoting faster ice-deformation rates over long times (Phillips and others, 2010, 2013).
While hydrofracture is recognised as an important contributor to the GrlS's mass loss, there is thought to be a discrepancy between its impact for different areas of the GrlS. Within ice-marginal, land-terminating regions $(\leq \sim 1000 \mathrm{~m}$ a.s.l.), any mid-summer accelerations in ice velocity are typically offset by reduced late-summer (Bartholomew and others, 2010; Hoffman and others, 2011; Sundal and others, 2011; van de Wal and others, 2015) or winter velocities (Sole and others, 2013). This is due to the evolution of the subglacial drainage system to higher hydraulic-efficiency channels, which can evacuate meltwater quickly, and in which there is a direct relation between effective pressure and increased discharge (Schoof, 2010; Chandler and others, 2013; Cowton and others, 2013; Andrews and others, 2014; Mayaud and others, 2014). This therefore tends to produce either a net decrease (van de Wal and others, 2008, 2015; Tedstone and others, 2015) or no net change in annual ice velocity within ice-marginal regions (Sole and others, 2013). However, if hydrofracture can occur within the inland, land-terminating regions of the GrlS (> 1000 $\mathrm{m}$ a.s.l.), substantial uncertainty surrounds its implications for ice-sheet dynamics, notably since field measurements indicate that increased summer velocities are not offset by reduced wintertime ones (Doyle and others, 2014). It is hypothesised that this is because hydraulicallyefficient subglacial drainage systems cannot form within inland regions due to the shallow ice-surface gradients, producing low hydraulic-potential gradients, and the thick overlying ice, producing high creep-closure rates (Bartholomew and others, 2011; Chandler and others, 2013; Meierbachtol and others, 2013; Dow and others, 2014, 2015; Moon and others, 2014). Instead, inefficient drainage here may persist year-round. This research therefore indicates that if SGLs 
can drain at higher elevations, the net overall slowdowns observed for the GrIS's marginal regions may not be observed further inland, potentially producing sustained mass loss into the future.

Meltwater volumes and the equilibrium line altitude are rising on the GrIS (Hanna and others, 2008; Howat and others, 2013), forced by rising air temperatures (Box and others, 2009; Hanna and others, 2012) and the increasing frequency of negative summer North Atlantic Oscillation indices (Fettweis and others, 2011, 2013). This has led to observations of increasingly numerous SGLs at higher elevations, with greater areas, in the past decades (Sundal and others, 2009; Liang and others, 2012; Howat and others, 2013; Fitzpatrick and others, 2014). Given that warming is projected to continue over the coming century (Collins and others, 2013), SGLs are expected to continue their inland migration and to increase their areas (Leeson and others, 2015; Ignéczi and others, 2016). With these increasingly numerous SGLs that cover greater areas inland, enhanced surface ablation (due to the darker SGLs compared with bare ice) over greater portions of the GrlS could produce a more negative mass balance; moreover, these SGLs could affect ice dynamics if the water contained within them can reach the ice-sheet interior, perhaps by rapid in situ drainage if hydrofracture can occur. Although uncertain, the inland ice-dynamic speed-ups may be so pronounced that they exceed the net velocity slowdowns currently observed for ice-marginal regions.

It therefore becomes evident from the above discussion that to model the GrlS's future reliably, understanding is required of (i) the likely future locations of SGLs, (ii) whether these SGLs can drain rapidly and (iii) if they drain rapidly, how the subglacial hydrological system will respond to the basal meltwater deliveries. Towards fulfilling these requirements, some studies (Sundal and others, 2009; Liang and others, 2012; Howat and others, 2013; Fitzpatrick and others, 2014; Pope, 2016) have linked the behaviour and properties of SGLs on the GrIS to climatic warming, with an assumption that understanding SGLs' past response to warming will help inform knowledge of their future development. However, of these studies, only three elicited long-term trends in the evolution of SGLs in response to climatic warming, which have sequentially improved our understanding of SGLs. Howat and others (2013) studied SGLs over a 40-year period using Landsat data for 12 study sites across the GrlS, presenting the first long-term record of SGL evolution. However, their study only examined the elevation change of the uppermost 0.1 $\mathrm{km}^{2}$ of SGL area, and no information was presented on the total or individual SGL area changes or the changing areaelevation distributions over time. In addition, the temporal resolution of the data in Howat and others' (2013) study was poor, with an average of only 2.25 images for each region between 1972 and 2000, although there were often more post-2000. Therefore, examining full regional changes to SGLs as well as using more images would likely have produced improved confidence in the study's conclusions. Fitzpatrick and others (2014) fulfilled the necessity for higher temporal resolution data by using MODerate-resolution Imaging Spectroradiometer (MODIS) imagery for the $6500 \mathrm{~km}^{2}$ Russell Glacier region of south-west Greenland over 11 years (2002-12). However, using MODIS imagery meant that smaller SGLs $\left(<0.0625 \mathrm{~km}^{2}\right.$, i.e. below MODIS's one-pixel threshold reporting size) were omitted from their record, despite the potential for these SGLs to form fractures to the bed (Krawczynski and others, 2009). Liang and others (2012) presented a similarly valuable decadal-length study of SGLs in West Greenland using MODIS, showing how SGLs changed alongside melt indices, but did not examine SGLs' inland advance over time. Finally, Sundal and others' (2009) study used MODIS data to improve our knowledge of the inland migration of SGLs, but this research was only for 4 years, meaning it was more difficult to elicit long-term trends. Collectively, these studies have produced a consistently improved understanding of the long-term evolution of SGLs on the GrIS, but because such studies are not more numerous, there remains significant uncertainty over the spatial and long-term (multidecadal) response of SGLs to warming across the GrIS. In addition, if more studies linked the knowledge of the changing SGL distribution to meteorological data (such as surface temperatures or other melt indices), this could help inform debates surrounding the future progression of SGLs inland as temperatures rise over the next century, something currently unaccounted for in models (Church and others, 2013).

Here, we extend this existing work by providing the most temporally extensive (1985-2016) and highest spatial resolution $(30 \mathrm{~m})$ existing examination of the response of SGLs to climatic warming within a $\sim 6200 \mathrm{~km}^{2}$ sector of the north-west GrlS. Our two main aims are to: (i) elicit changes to the spatial distribution and coverage of SGLs in the region from 1985 to 2016; and (ii) evaluate these patterns within the context of regional surface-temperature changes. We choose a north-western sector of the GrlS because few studies have focused on SGLs in the region despite it including $19 \%$ of SGLs on the GrIS, the second largest frequency after the south-western area (Selmes and others, 2011), which has been the focus of previous research of this type (Sundal and others, 2009; Liang and others, 2012; Fitzpatrick and others, 2014). The study site within the Qaasuitsup municipality of Greenland encompasses the outlets of Alison Gletscher, Illlullip Sermia and Cornell Glacier, and extends from the ice margin to just below 1800 m a.s.l. (Fig. 1).

\section{DATA AND METHODS}

\section{Satellite imagery data collection and pre-processing}

Many studies of SGLs on the GrIS have used MODIS data (e.g. Selmes and others, 2011, 2013; Liang and others, 2012; Fitzpatrick and others, 2014; Williamson and others, 2017). However, we opted for Landsat data because its finer $30 \mathrm{~m}$ spatial resolution (in the visible optical bands) allows much smaller SGLs to be resolved than with coarser resolution $250 \mathrm{~m}$ or $500 \mathrm{~m}$ MODIS data (i.e. minimum resolvable Landsat SGL size of $0.0009 \mathrm{~km}^{2}$ compared with a minimum MODIS resolvable SGL size of $0.0625 \mathrm{~km}^{2}$ ). It was deemed important to capture these small $\left(<0.1 \mathrm{~km}^{2}\right)$ SGLs in this study since they account for as much as $7.5 \%$ (Fitzpatrick and others, 2014) or 12\% (Sundal and others, 2009) of the total SGL area during the mid-melt season, and because they may be able to initiate hydrofracture based on theoretical estimates (Krawczynski and others, 2009). In addition, the Landsat record extends further back than the MODIS one (i.e. 1972 for Landsat compared with 


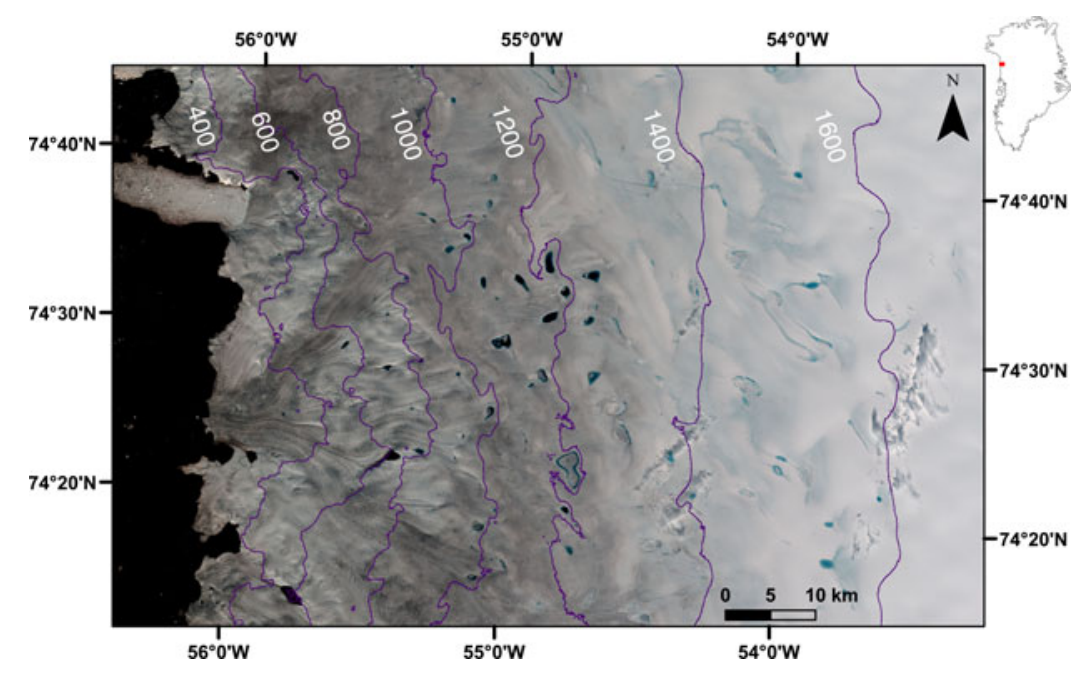

Fig. 1. The study site in north-west Greenland. Top-right inset shows the location of the study site (red square) within Greenland (black outline). The background is a false-colour red-green-blue (RGB) Landsat-8 Operational Land Imager (OLI) image (path: 019; row: 007) collected on 28 July 2015 (band $2=$ red, band $3=$ green, band $4=$ blue). The purple lines indicate ice-surface elevation contours (in $\mathrm{m}$ a. s.l.) derived from the Greenland Ice Mapping Project (GIMP) DEM from Howat and others (2014).

2000 for MODIS), allowing the long-term SGL evolution to be examined more comprehensively.

The Landsat images were acquired from the USGS Earth Explorer interface (http://earthexplorer.usgs.gov/). Since SGLs are highly transient, with an average 24-day lifespan (Johansson and others, 2013), we only downloaded Landsat data for the years satisfying the condition of having at least four cloud-free images during July and August, maximising the probability of capturing all of the SGLs present within the region during the summer. While we realised that many small $\left(<0.125 \mathrm{~km}^{2}\right)$ SGLs form in mid- to late June, and may reach their maximum extents before the July images, the rapid drainage of these small lakes typically occurs in early to mid-July (Miles and others, 2017; their Table 2), meaning that these lakes would usually not have disappeared from the ice-sheet surface prior to the July and August imagery; thus, they would have been included in our analysis. Any not included in the analysis were likely to have been small (both in number and in area), as is usually true early in the melt season, meaning that the overall impact on this study's results would be minimal. The images needed to be manually reviewed for cloud cover since the study site covered only a portion of an entire Landsat scene, preventing the use of image filtering using the interface's built-in cloud-cover algorithm, which could have led to omission of some valid images. There were 44 images meeting these criteria (Table S1), and they were from 1985, 1988, 1990 and 1994 (Landsat-5 Thematic Mapper (TM)), 2000, 2007 and 2009 (Landsat-7 Enhanced Thematic Mapper+(ETM+)), and 2014, 2015 and 2016 (Landsat-8 OLI). These images were level-1T products, meaning no radiometric correction was required. However, given that the image's geometric accuracy was crucial to ensure accurate reporting of the surface elevations of individual SGLs, each image was checked for geometric distortion against the 2016 image, which was regarded as geometrically rectified; geometric rectification was conducted in ArcGIS where the distortion from the 2016 reference image exceed one pixel (i.e. $30 \mathrm{~m}$ ). This process involved fixing four control points on nunataks and then shifting any distorted images (with a polynomial transformation) to match the 2016 reference framework. Due to the Scan Line Corrector (SLC) failure on Landsat-7 ETM+ after 2002, the images from 2007 and 2009 could only be used to determine the maximum elevations of SGLs and not for any other analysis. All of the images were cropped to the study area using a georeferenced mask.

To ensure that the numbers of SGLs reported in each year were not a product of the images being available during only earlier or later parts of the melt season, we checked the image dataset for systematic bias towards earlier or later parts of the season. This was in addition to our inclusion of only the years where at least four images were available, as mentioned above. We recognise that comparing dates alone is only a first-order approximation for image bias towards specific periods of the season since it is plausible that early or late melt episodes within the melt season can occur. A oneway analysis of variance test was conducted after the image dates were converted to days of the year. This revealed that the yearly means of the image dates were not significantly different at the $90 \%$ confidence interval $\left(F_{(9,34)}=\right.$ $0.590 ; p=0.785)$ and that the standard deviations were similar between years (mean of standard deviations $=17.3$ days; range of standard deviations $=13.7-23.0$ days). Table S2 documents full comparisons of the yearly means and variance. We could therefore be confident that the variation in image dates between years would not considerably bias our study's results.

\section{SGL identification and spatial analysis}

\section{SGL delineation technique}

Various automatic methods exist for delineating SGLs, such as static band classification (Box and Ski, 2007; Arnold and others, 2014; Banwell and others, 2014; Fitzpatrick and others, 2014), the Normalised Difference Water Index (e.g. Yang and Smith, 2013; Moussavi and others, 2016; Miles and others, 2017), dynamic band thresholding (Selmes and others, 2011, 2013; Everett and others, 2016; Williamson and others, 2017), a global and local classification approach (Yang and others, 2015), image-histogram classification (Liang and others, 2012; Howat and others, 2013) and 
object-oriented classification (Johansson and Brown, 2013). While these automatic methods are less time-consuming compared with manual delimitation, they produce less accurate SGL boundaries even though the manual method is subject to some user bias (Leeson and others, 2013). Using relatively high-resolution Landsat imagery is likely to reduce this user bias more than if coarser imagery, such as that from MODIS, was used since the contrast between the darker SGL water and the brighter surrounding ice will not be altered by the low pixel resolution, as is the case with MODIS (Williamson and others, 2017).

We therefore selected to manually delineate SGL boundaries from the Landsat false-colour RGB composites, in line with previous studies (McMillan and others, 2007; Hoffman and others, 2011; Lampkin, 2011; Lampkin and VanderBerg, 2011; Langley and others, 2016). We adopted a set of uniform fixed guidelines, similar to Lampkin and VanderBerg (2011), to ensure the consistency of our technique across all of the images: (i) rectilinear and curvilinear features were excluded since they were believed to represent supraglacial meltwater streams; and (ii) very small features where the SGL boundaries could not be discerned were omitted. For any SGLs that had ice floating over their centres, their areas were calculated for the water-covered area only rather than assuming that the ice-covered areas also represented water; this may have slightly underestimated total and individual SGL area, particularly since icecovered SGLs tend to be larger than ice-free ones (Johansson and others, 2013). We calculated the errors on the manually delineated areas following McMillan and others (2007); these error bounds were likely to be conservative since their method assumes that, for each pixel, the area is either overestimated or underestimated, when a combination of the two is more likely. From the individual SGL polygons, a binary (SGL and non-SGL) mask was created for each image, and then these masks were superimposed for each year to produce a maximum extent of the SGLs observed across all of the images in July and August of that year (Fig. S1). We acknowledge that the 'maximum extent' could not capture all of the water present on the ice-sheet surface at any point within the melt season, but simply represented a best estimate of this value.

\section{Derivation of annual SGL metrics}

From the maximum extent masks of SGLs within July and August from all of the available imagery each year, various metrics relating to the SGLs could be calculated. To calculate the elevations of SGLs for all of the years, we used the GIMP DEM (Howat and others, 2014). We used Howat and others' (2014) error bound of $\pm 12.7 \mathrm{~m}$ for the surface-elevation measurements, which was calculated with the RMSD between the GIMP measurements and surface measurements from the Ice, Cloud and land Elevation Satellite (ICESat). Elevations were taken at SGL centroids, and we used nine discrete elevation bands at $200 \mathrm{~m}$ increments to investigate SGLs' altitudinal variation over time. We note that using the same DEM, which was derived over the period 200309, for the entire study period may have introduced errors due to thinning of the north-western GrIS in 1992-2002 (Zwally and others, 2005), 1997-2003 (Krabill and others, 2004), 2003-07 (Pritchard and others, 2009; Zwally and others, 2011), and 2001-14 (Helm and others, 2014; McMillan and others, 2016). This indicated that surface elevations in 1985-2007 were likely to have been underestimated, while those in 2007-16 were likely to have been overestimated. However, the overall magnitude of these errors was tens of metres, which was not sufficiently high to alter the conclusions of the study.

Total SGL area, and the distribution of SGL area by elevation band, was also derived by integrating the individual SGL areas across the (relevant portions of the) image. To derive SGL volume data, we used an empirically derived SGL area-volume scaling relationship rather than a more complex empirical depth-reflectance technique (Box and Ski, 2007; Fitzpatrick and others, 2014), or a physicallybased approach applied to the image surface-reflectance data (Sneed and Hamilton, 2007; Georgiou and others, 2009; Morriss and others, 2013; Arnold and others, 2014; Banwell and others, 2014; Ignéczi and others, 2016; Langley and others, 2016; Moussavi and others, 2016; Pope, 2016; Pope and others, 2016; Williamson and others, 2017). We opted for this simple SGL area-volume scaling relationship since previous work indicates a strong and significant positive linear relationship between SGL area and volume (Box and Ski, 2007; Georgiou and others, 2009; Morriss and others, 2013; Williamson and others, 2017). While such linear relationships do not always best represent the relationship between SGL areas and volumes (Williamson and others, 2017) and may not apply for the higher ice-surface elevations (where SGLs may be shallower due to the smaller ice-surface depressions), the errors derived from applying this simple relationship would be consistent across the study period. To derive the scaling relationship, we used SGL area and volume data from Box and Ski (2007) and Georgiou and others (2009) (Fig. S2). From these data, we obtained a strong positive correlation between SGL area and volume $(r=0.931 ; p<0.001)$, with SGL area explaining $\sim 87 \%$ of the variance in SGL volume $\left(R^{2}=0.867 ; p<0.001\right)$. We then scaled SGL area to volume using the equation of the linear regression line (Fig. S2):

$$
\text { SGL volume }\left(\times 10^{6} \mathrm{~m}^{3}\right)=4.7105 \times \text { SGL area }\left(\mathrm{km}^{2}\right) \text {. }
$$

\section{Surface-temperature data collection}

To link the observed changes in the spatial distribution of SGLs over the study period to climatic forcings, we used two surface-temperature datasets as proxies: for the period 2000-16, monthly surface-temperature data for the region were derived from MODIS; however, since these data were unavailable prior to 2000, for the period 1873-1999, nearby automatic weather station (AWS) data were used. Ideally, we would have used the same data for the entire study period, but since MODIS data were collected locally to the region (and so had less error associated with them), we used these data where they were available, instead of using AWS data for the entire period. We required the long-term AWS data to derive to a baseline 20th-century temperature, which would allow the calculation of the surfacetemperature anomaly for our study period by comparing the surface-temperature value for each year against the baseline. The baseline was derived as the average of the summer surface temperature as measured with the AWS data from 1901-2000. We used these surface-temperature anomalies as proxies for total meltwater volume production in different 
years, but note that surface runoff is a product not only of surface temperatures but also of a suite of other factors, including accumulation rates and incoming solar radiation; this may have impacted the total variance explained by the surface-temperature anomalies.

\section{MODIS temperature data}

The MOD11C3 Land Surface Temperature, acquired by MODIS's Terra satellite, was selected since it provides monthly global composited and averaged temperature values in a $0.05^{\circ} \times 0.05^{\circ}$ (i.e. $5600 \mathrm{~m} \times 5600 \mathrm{~m}$ ) latitude/longitude climate modelling grid. These data were downloaded manually for July and August from 2000-16 from the USGS's LPDAAC Data Pool (https://lpdaac.usgs.gov/data_access/ data_pool/). Raw digital numbers $(d n)$ were then extracted from a $9 \times 17$-point grid over the study area and averaged to produce a monthly mean temperature within the study region. Surface temperature was obtained with:

$$
T=(d n \times s f)-273.15
$$

where $T$ was surface temperature (in ${ }^{\circ} \mathrm{C}$ ), sf was the data scale factor (0.02), and 273.15 was used to convert from Kelvin to degrees Celsius.

\section{Weather station temperature data}

Monthly air temperature data were available for ten AWSs around the periphery of the GrlS, with two in north-west Greenland proximal to the study site: one at Pituffik (number 4202) and a second at Upernavik (number 4211) (Cappelen and others, 2015). To determine which of the AWS data were most representative of the weather at the study site, we downloaded data for these two AWSs from the Danish Meteorological Institute (http://research.dmi.dk/ data/) for July and August for the period 1873-2015 (at Pituffik) and 1873-2014 (at Upernarvik). The AWS data were averaged for July and August and then compared against the average July and August surface temperatures derived from MODIS (see the section 'MODIS temperature data') during the overlapping years (2000-15 for Pituffik or 2000-14 for Upernarvik). We found that data from Upernavik $\left(r=0.772 ; p=0.01 ; R^{2}=0.596\right)$ produced a better correlation and explained more of the variance in the MODIS data than the data from Pituffik $(r=0.555 ; p=$ $0.260 ; R^{2}=0.308$ ) and so these data were used for the period 1985-99 (Fig. S3). We used the linear regression relationship $(y=0.0927(x)-7.5548)$ from the AWS-to-MODIS temperature relationship to scale the 1873-1999 AWS data to ensure consistency with the MODIS values for the 2000-16 period. We calculated the standard error of the estimate, which measures the accuracy of measurements derived from a linear regression line, to provide error bounds on the 1873-1999 AWS data; since the MODIS data are effectively ground-truth data, we did not calculate error bounds for them.

\section{Statistical analyses}

We used four statistical techniques: (i) the area-weighted arithmetic mean to determine the mean elevation of SGLs for each measurement year; (ii) the Pearson's productmoment correlation coefficient $(r)$ to assess the strength and nature of linear association between the measurement year and SGL metrics, and between summer surface-temperature anomalies and SGL metrics; (iii) the coefficient of determination $\left(R^{2}\right)$ to quantify the extent to which surface-temperature anomalies explained the variance in SGL characteristics, and; (iv) multiple linear regression. Multiple linear regression involved setting the maximum areal extent of SGLs across the whole region as the response variable and then modelling the relationship between this variable and three explanatory variables. The three explanatory variables were the maximum areal extent of SGLs within the low, medium and high elevation bands (corresponding to $<600 \mathrm{~m}$ a.s.l., 600-1199 $\mathrm{m}$ a.s.I. and $\geq 1200 \mathrm{~m}$ a.s.l., respectively). The standardised beta coefficients $(\beta)$ were used to indicate the number of standard deviations from the mean by which the response variable changes for an increase in the explanatory variable by an increment of one standard deviation from the mean. It thus denoted the relative contribution of each explanatory variable to the response variable, and therefore indicated the extent to which changes to the maximum areal extent of SGLs within the three elevation bands produced the changes to maximum SGL extent observed across the region.

Prior to the statistical analysis, we conducted a series of assumption checks to provide high confidence in the results derived from the analysis. Our method involved: (i) checking for linearity of relationships and the presence of notable outliers by qualitatively assessing scatterplots; (ii) checking the data normality using the Shapiro-Wilk test; (iii) verifying that there was no autocorrelation with the Durbin-Watson statistic; and; (iv) in the case of multiple regression, testing for collinearity by calculating $r$ values for the independent variables (Weisberg, 2005). Any datasets failing these tests were discarded before further analysis. For all of the statistical tests, because of the small sample size in the study, we set the confidence interval at $90 \%$, equivalent to a probability indicator $(p)$ of 0.1 . We also identified test results that were statistically significant with higher confidence intervals (i.e. $95 \%$ or $99 \%, p=0.05$ or 0.01 , respectively).

\section{RESULTS}

\section{Changes to the spatial distribution and coverage of SGLs}

SGL elevation

Two years (2007 and 2009) were affected by the SLC failure on Landsat-7, meaning only the maximum SGL elevation could be ascertained for them. An average of 1014 SGLs (total number across all years $=8115$, average SGL area across all years $=0.15 \mathrm{~km}^{2}$ ) was identified for each year from the eight maximum SGL extent images unaffected by the SLC failure (Table 1).

Maximum SGL elevation increased by $418 \mathrm{~m}$ between 1985 (1252 $\mathrm{m}$ a.s.l.) and 2016 (1670 $\mathrm{m}$ a.s.l.), with the maximum observed elevation being $1672 \mathrm{~m}$ a.s.l. in summer 2015 (Figs 2, 3a). This long-term trend was confirmed by a strong correlation $(r=0.960 ; p=0.000)$. Table 2 shows that the maximum elevation of SGLs changed at a rate of $13.5 \mathrm{~m} \mathrm{a}^{-1}$; however, this rate was nearly three times higher in 2000-16 compared with 1985-99. The area-weighted SGL mean elevation also increased by $299 \mathrm{~m}$ between 1985 (817 m a.s.l.) and 2016 (1116 $\mathrm{m}$ a.s.l.), which is of a similar magnitude but $\sim 100 \mathrm{~m}$ less than the increase to maximum SGL elevation. Again, a 
Table 1. Number, size and total area of the SGLs (including those that would not have been recorded by MODIS, i.e. $<0.125 \mathrm{~km}^{2}$ in area) identified over the years of the study period.

\begin{tabular}{|c|c|c|c|c|c|c|c|}
\hline Year & $\begin{array}{l}\text { SGL } \\
\text { number }\end{array}$ & $\begin{array}{l}\text { Total } \\
\text { SGL area } \\
\left(\mathrm{km}^{2}\right)\end{array}$ & $\begin{array}{l}\text { Mean individual } \\
\text { SGL area } \\
\left(\mathrm{km}^{2}\right)\end{array}$ & $\begin{array}{l}\text { Maximum individual } \\
\text { SGL area } \\
\left(\mathrm{km}^{2}\right)\end{array}$ & $\begin{array}{l}\text { Number of SGLs } \\
\text { with areas } \\
<0.125 \mathrm{~km}^{2}\end{array}$ & $\begin{array}{l}\text { Total area of SGLs } \\
\text { with areas } \\
<0.125 \mathrm{~km}^{2}\end{array}$ & $\begin{array}{l}\% \text { of total SGL area } \\
\text { accounted for by SGLs } \\
<0.125 \mathrm{~km}^{2}\end{array}$ \\
\hline 1985 & 753 & 45.1 & 0.18 & 2.3 & 157 & 6.0 & 13.3 \\
\hline 1988 & 1179 & 66.8 & 0.17 & 1.9 & 261 & 9.3 & 13.9 \\
\hline 1990 & 1176 & 45.2 & 0.12 & 2.2 & 307 & 7.6 & 16.8 \\
\hline 1994 & 1218 & 57.5 & 0.14 & 2.8 & 287 & 9.1 & 15.7 \\
\hline 2014 & 1074 & 83.0 & 0.07 & 3.5 & 213 & 8.2 & 9.9 \\
\hline 2015 & 867 & 94.8 & 0.10 & 2.9 & 165 & 6.1 & 7.0 \\
\hline 2016 & 969 & 87.1 & 0.27 & 4.1 & 185 & 7.7 & 8.1 \\
\hline Mean & 1014 & 66.6 & 0.15 & 2.7 & 221 & 7.7 & 12.3 \\
\hline
\end{tabular}

strong correlation $(r=0.935 ; p=0.001)$ was associated with the SGL progression to higher mean elevations. The rate of change to the area-weighted mean elevation was similar $(<5 \%$ different $)$ to that observed for maximum SGL elevations over the entire period, with a similarly accelerated rate of more than double after 2000 compared with beforehand (Table 2).

\section{SGL coverage}

The maximum areal extent of SGLs nearly doubled over the 32-year period from 45.1 to $87.1 \mathrm{~km}^{2}$, with a maximum extent of $>90 \mathrm{~km}^{2}$ in 2015 (Table 1 and Fig. 3c). A strong positive correlation $(r=0.883 ; p=0.004)$ confirmed this relationship. In addition, individual SGLs tended to grow in size towards the end of the study period, with typically higher mean sizes across the whole region (mean $=0.13$ $\mathrm{km}^{2}$ pre-2000 compared with mean $=0.15 \mathrm{~km}^{2}$ post-2000, although mean size in 2016 was much higher at $0.27 \mathrm{~km}^{2}$ ) and maximum SGL sizes (mean $=2.28 \mathrm{~km}^{2}$ until $2000 \mathrm{com}$ pared with mean $=3.50 \mathrm{~km}^{2}$ in 2014, 2015 and 2016) (Table 1). Within the later period (2014-16), we observed increasing variability in the size of the identified SGLs; for example, even though in 2015 the total regional SGL area was higher than in $2016\left(95 \mathrm{~km}^{2}\right.$ in 2015 compared with $87 \mathrm{~km}^{2}$ in 2016), the maximum individual SGL area was higher in $2016\left(4.1 \mathrm{~km}^{2}\right.$ in 2016 compared with $2.9 \mathrm{~km}^{2}$ in 2015). The rate of increase to the maximum areal extent accelerated more than fourfold from $0.53 \mathrm{~km}^{2} \mathrm{a}^{-1}(1985-$ 99) to $2.13 \mathrm{~km}^{2} \mathrm{a}^{-1}$ (2000-16) (Table 2). Since the SGL volumes were derived using a linear regression relationship, the changes to SGL volumes mirrored those to SGL areas: volumes approximately doubled from $\sim 45 \times 10^{6} \mathrm{~m}^{3}$ in 1985 to $\sim 90 \times 10^{6} \mathrm{~m}^{3}$ in 2016 , with a statistically significant $(r=0.883 ; p=0.004)$ rate of change $\left(1.35 \times 10^{6} \mathrm{~m}^{3} \mathrm{a}^{-1}\right)$ over the entire period, with a fourfold accelerated rate of change post-2000 (Table 2). These changes were primarily driven by increases to SGL areas and volumes within the high elevation bands, notably those $\geq 1200 \mathrm{~m}$ a.s.l. (Fig. 4). For example, SGL area within the 1200-1399 m a.s.l. band remained approximately constant until 2014, when there were notable increases here, as well as large increases to SGL areas within the $\geq 1400 \mathrm{~m}$ a.s.l. elevation bands (Fig. 4).

In addition, we identified many SGLs (mean $=221$ per image; maximum $=307$ in 1990; minimum $=157$ in 1985) under $0.125 \mathrm{~km}^{2}$ in size (i.e. those unresolvable by
MODIS depending on whether one or two MODIS pixels can be confidently regarded as a SGL (Selmes and others, 2011, 2013; Fitzpatrick and others, 2014; Williamson and others, 2017)). These SGLs represented relatively high proportions of the total regional SGL area (mean $=12.3 \%$, equivalent to an area of $7.7 \mathrm{~km}^{2}$, with consistently $>5 \%$ coverage relative to the total) (Table 1 ).

The individual $200 \mathrm{~m}$ a.s.l. elevation bands were combined into broader categories of low $(<600 \mathrm{~m}$ a.s.l.), medium (600-1199 $\mathrm{m}$ a.s.l.) and high ( $\geq 1200 \mathrm{~m}$ a.s.I.) surface elevations to assess the wider-scale patterns. At low elevations, the maximum areal extent of SGLs did not change significantly over the period $(r=-0.554 ; p=$ $0.155)$, even though there was a large (almost quadruple) range in the area from $4.30 \mathrm{~km}^{2}$ (in 1990) to $16.50 \mathrm{~km}^{2}$ (in 1988) and an apparent downwards trend (Figs 2, 3d). A similar pattern was observed at medium elevations (Figs 2, 3e): while there appeared to be an upwards trend, this could not be confirmed statistically $(r=0.571 ; p=0.139)$. There was also less relative variation for the medium elevations between the minimum $\left(34.9 \mathrm{~km}^{2}\right.$ in 1985) and maximum $\left(44.8 \mathrm{~km}^{2}\right.$ in 1994) values over the study period. The rates of change at the low and medium elevations were also not noteworthy, especially for the low elevations, with the rate showing almost no change during the study period (Table 2). Contrasting with the observations for low and medium elevations, the maximum areal extent at high elevations showed significant $(r=0.932 ; p=0.000)$ increases of $>2750 \%$ over the period from $1.21 \mathrm{~km}^{2}$ in 1985 to $34.9 \mathrm{~km}^{2}$ in 2016 (Figs 2, 3f). This change comprised only small changes to the maximum areal extent of SGLs at high elevations between 1985 and 1999 (with values always remaining below $6 \mathrm{~km}^{2}$ ), but substantial increases post-2000 (although data were only available for the years 2014-16), with values consistently above $30 \mathrm{~km}^{2}$ in the most recent (2014, 2015 and 2016) summers (Fig. 3f). This therefore produced a very high rate of increase in the later period $\left(1.88 \mathrm{~km}^{2} \mathrm{a}^{-1}\right.$ in 2000-16) compared with the earlier one $\left(0.23 \mathrm{~km}^{2} \mathrm{a}^{-1}\right.$ in 1985-99), representing an eightfold and nearly an order of magnitude increase (Table 2). Examining the $200 \mathrm{~m}$ a.s.l. elevation banding revealed that this late (post-2010) acceleration was attributable to increases in the SGL area within the 1200-1399 m a.s.I. elevation band, and the unprecedented appearance of SGLs within the 1400-1599 $\mathrm{m}$ a.s.l. and $\geq 1600 \mathrm{~m}$ a.s.l. elevation bands (Figs 2, 4). 

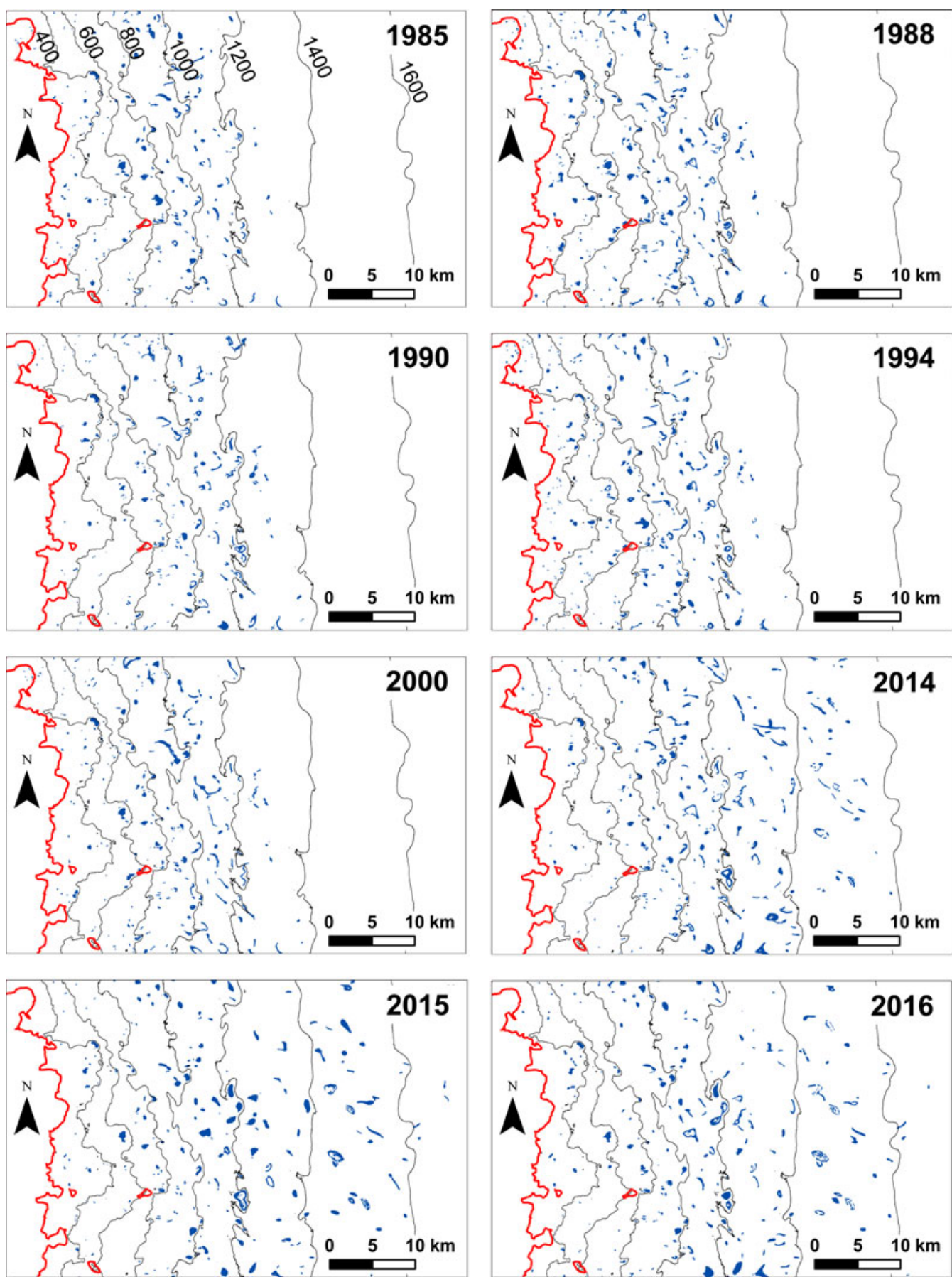

Fig. 2. Spatial distribution of SGLs across the study region for the 8 years unaffected by the SLC failure. The blue polygons represent maximum annual SGL extents, the red line shows the GrIS margin, and the black lines show ice-surface elevation contours (in $\mathrm{m}$ a.s.l.) from Howat and others (2014). Contours are only labelled on the 1985 panel, but are consistent for all years. The total areal extent of each panel is equivalent to that shown in Figure 1.

Relative to the total SGL area change of $42.0 \mathrm{~km}^{2}$ over the study period, changes to the SGL area at the higher elevations accounted for a greater portion $\left(80.1 \%\right.$ or $\left.33.7 \mathrm{~km}^{2}\right)$ of the total change than changes to SGLs at the medium $(23.8 \%$ or $\left.10.0 \mathrm{~km}^{2}\right)$ or low elevations $\left(-3.81 \%\right.$ or $\left.-1.60 \mathrm{~km}^{2}\right)$. Multiple-regression analysis confirmed these patterns: the maximum areal extent of SGLs was predominantly influenced by the area at high elevations $(\beta=0.936 ; p=0.000)$ rather than at medium $(\beta=0.214 ; p=0.000)$ or low elevations $(\beta=0.202 ; p=0.000)$. The same $\beta$ values were obtained for the changes to regional SGL volumes for the differing elevation bands.

\section{The influence of surface-temperature changes on SGLs}

\section{Changes to regional surface temperature}

Recent (1985-2016) changes to surface temperatures in the region were contextualised against the long-term (18732016) record (Fig. 5). This time series showed that surfacetemperature anomalies increased by $4.24^{\circ} \mathrm{C}$ from $-2.02^{\circ} \mathrm{C}$ in 1873 to $+2.22^{\circ} \mathrm{C}$ in 2016 , and, in $\sim 1945$, switched from being generally negative to generally positive (Fig. 5). This long-term warming trend was statistically significant $(r=$ $0.505 ; p=0.000$ ). The 10 -year moving average showed that the increase in surface-temperature anomalies was 

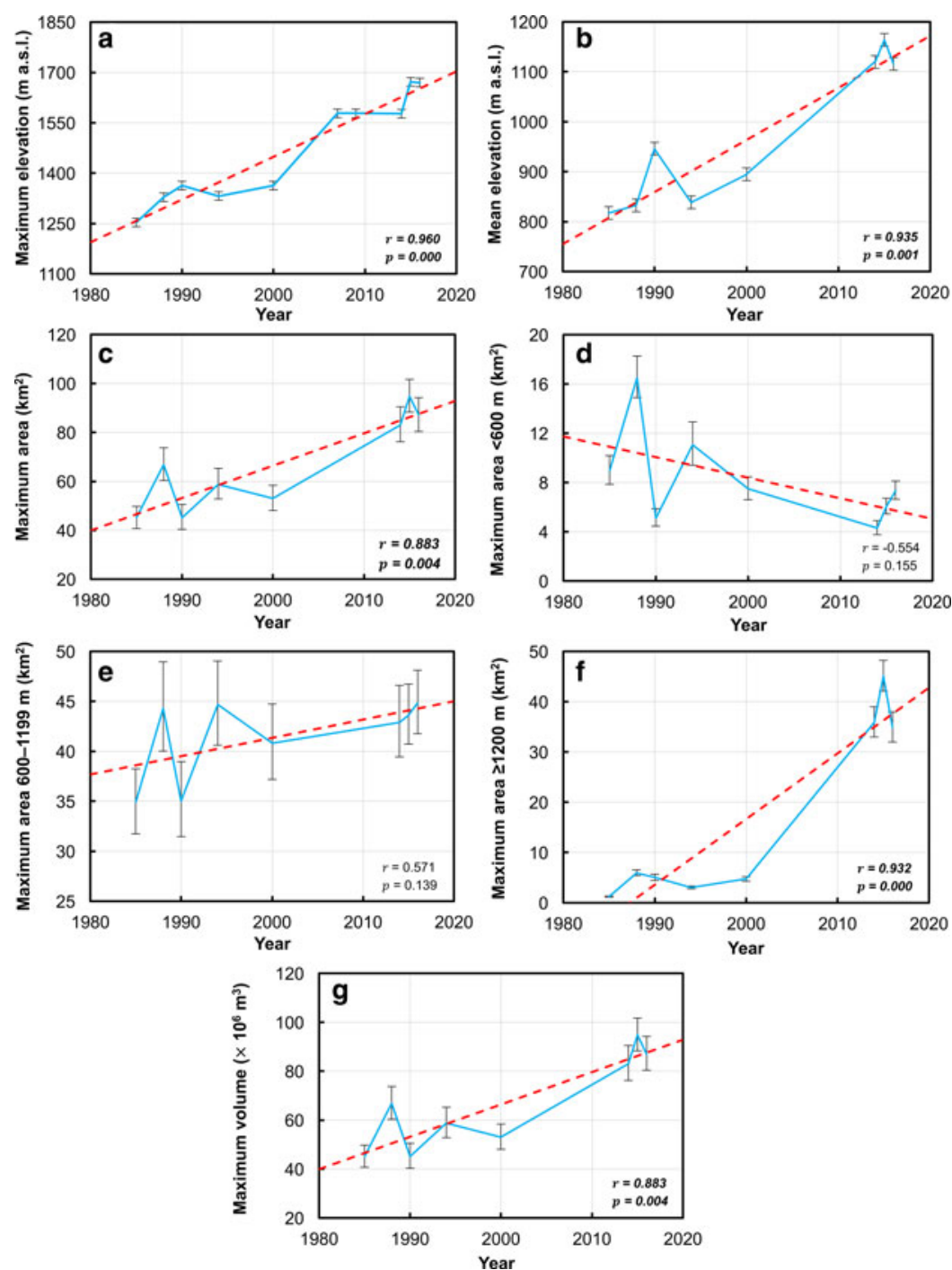

Fig. 3. Changes to SGL metrics in 1985-2016: (a) maximum SGL elevation, (b) area-weighted mean SGL elevation, (c) maximum areal SGL extent across the whole region, (d) maximum areal SGL extent at low surface elevations, (e) maximum areal SGL extent at medium surface elevations, (f) maximum areal SGL extent at high surface elevations, and (g) maximum volumetric SGL extent across the whole region. Blue solid lines are shown to connect the data points, while red dashed lines show ordinary least-squares (OLS) linear regression lines. Significant $r$ and $R^{2}$ values at above the $95 \%$ confidence interval $(p<0.05)$ are highlighted in bold italicised text on each panel. Black error bars for SGL areas and volumes are derived according to the section 'SGL delineation technique' and black error bars for elevations are derived according to the section 'Derivation of annual SGL lake metrics'.

most substantial post-2000 as the rate of change in 2001-16 $\left(0.148{ }^{\circ} \mathrm{C} \mathrm{a}^{-1}\right)$ was two orders of magnitude greater than that in $1873-2000\left(0.007^{\circ} \mathrm{C} \mathrm{a}^{-1}\right)$. Moreover, surface-temperature anomalies during the 21 st century were the highest on record, with the average anomaly in $2000-16\left(+1.90^{\circ} \mathrm{C}\right)$ being more than double the average in any previous decade, and comparing with the average from 1873 to 1999 of $-0.18^{\circ} \mathrm{C}$. Finally, 9 of the 10 warmest years in the entire record occurred during the 21 st century (Fig. 5). Table 3 shows the summer surface-temperature anomalies for the years of this study: the highest values occurred in 2007, 2009, 2015 and 2016; the lowest were in 1990 and 2000. The mean and minimum surface-temperature anomalies for the years of this study were +1.27 and $-0.73^{\circ} \mathrm{C}$, respectively, but there was some spread in the data $\left(\sigma=1.39^{\circ} \mathrm{C}\right)$ (Table 3).

The influence of surface temperatures on SGL elevation When summer surface-temperature anomalies were highest, the maximum elevation of SGLs was also higher: for example, the extremely high SGL elevation values (relative to a mean maximum elevation over the 1985-2016 period of $1471 \mathrm{~m}$ a.s.l.) of $1578 \mathrm{~m}$ a.s.l. in $2007,1578 \mathrm{~m}$ a.s.l. in 2009, $1672 \mathrm{~m}$ a.s.l. in 2015 and $1670 \mathrm{~m}$ a.s.l. in 2016 were accompanied by high positive surface-temperature anomalies of $+3.34,+2.65,+2.18$ and $+2.28^{\circ} \mathrm{C}$, respectively (Fig. 6a). Similarly, the extremely low values when maximum SGL elevations were only $1363 \mathrm{~m}$ a.s.l. in both 1990 and 2000 were accompanied by the most negative surface-temperature anomalies $\left(-0.73\right.$ and $-0.61^{\circ} \mathrm{C}$, respectively). These patterns were confirmed by a moderate and statistically significant positive correlation $(r=0.637 ; p=0.048)$ between maximum SGL elevation and surface-temperature anomalies. Furthermore, linear regression indicated that the surface-temperature anomalies explained $40.6 \%$ of the variance in maximum SGL elevations $\left(R^{2}=0.406 ; p=0.048\right)$ (Fig. 6a).

However, there was no statistically significant relationship $(r=0.471 ; p=0.239)$ between surface-temperature anomalies and the area-weighted mean SGL elevation (Fig. 6b). This 
Table 2. The rates of change to annual SGL metrics within the study region over the full $\left(t_{1}+t_{2}\right)$, early $\left(t_{1}\right)$, and late $\left(t_{2}\right)$ periods, as well the relative rate of change $\left(t_{2} / t_{1}\right)$ from the early to late periods.

\begin{tabular}{|c|c|c|c|c|}
\hline Rate of change of SGL metric & $1985-2016\left(t_{1}+t_{2}\right)$ & 1985-99 $\left(t_{1}\right)$ & $2000-16\left(t_{2}\right)$ & Relative rate of change $\left(t_{2} / t_{1}\right)$ \\
\hline Maximum elevation $\left(\mathrm{m} \mathrm{a}^{-1}\right)$ & 13.5 & 6.88 & 19.2 & 2.79 \\
\hline Mean elevation $\left(\mathrm{m} \mathrm{a}^{-1}\right)$ & 9.63 & 5.17 & 13.8 & 2.67 \\
\hline Total area $\left(\mathrm{km}^{2} \mathrm{a}^{-1}\right)$ & 1.35 & 0.53 & 2.13 & 4.01 \\
\hline Area $<600 \mathrm{~m}$ a.s.l. $\left(\mathrm{km}^{2} \mathrm{a}^{1}\right)$ & -0.05 & -0.10 & 0.00 & 0.00 \\
\hline Area $600-1199 \mathrm{~m}$ a.s.l. $\left(\mathrm{km}^{2} \mathrm{a}^{-1}\right)$ & 0.32 & 0.40 & 0.25 & 0.62 \\
\hline Area $\geq 1200 \mathrm{~m}$ a.s.l. $\left(\mathrm{km}^{2} \mathrm{a}^{-1}\right)$ & 1.09 & 0.23 & 1.88 & 8.17 \\
\hline Volume $\left(\times 10^{6} \mathrm{~m}^{3} \mathrm{a}^{-1}\right)$ & 1.35 & 0.53 & 2.13 & 4.01 \\
\hline
\end{tabular}

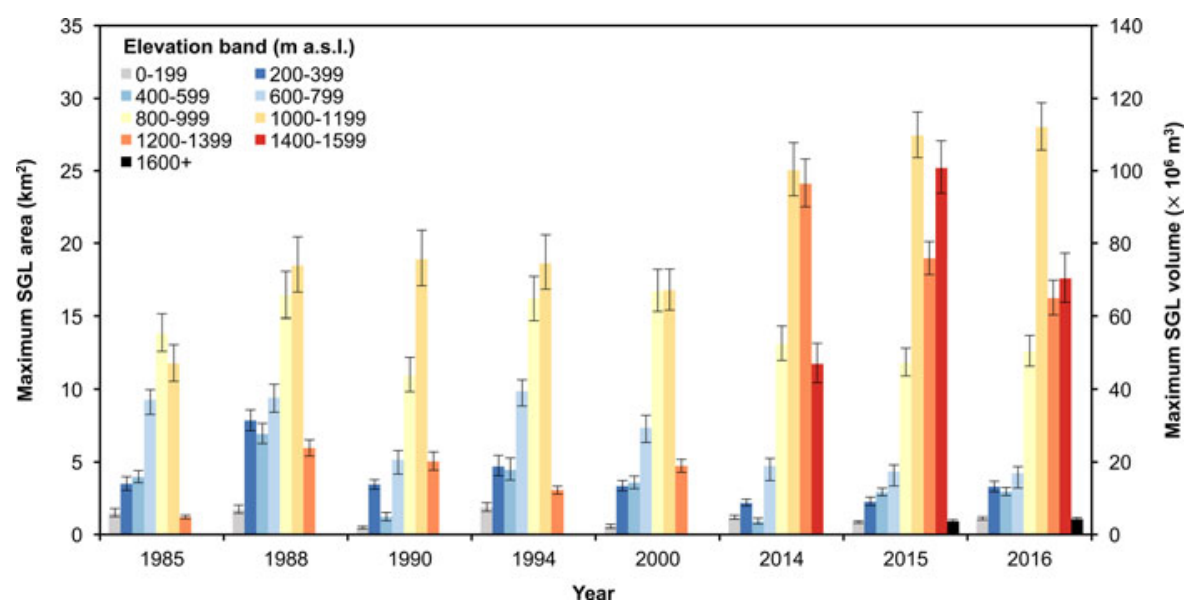

Fig. 4. Maximum areal ( $y_{1}$-axis) and volumetric ( $y_{2}$-axis) regional extent of SGLs within individual $200 \mathrm{~m}$ ice-surface elevation bands (cf. Fig. 2) over the study period. Black error bars for SGL areas and volumes are derived according to the section 'SGL delineation technique'.

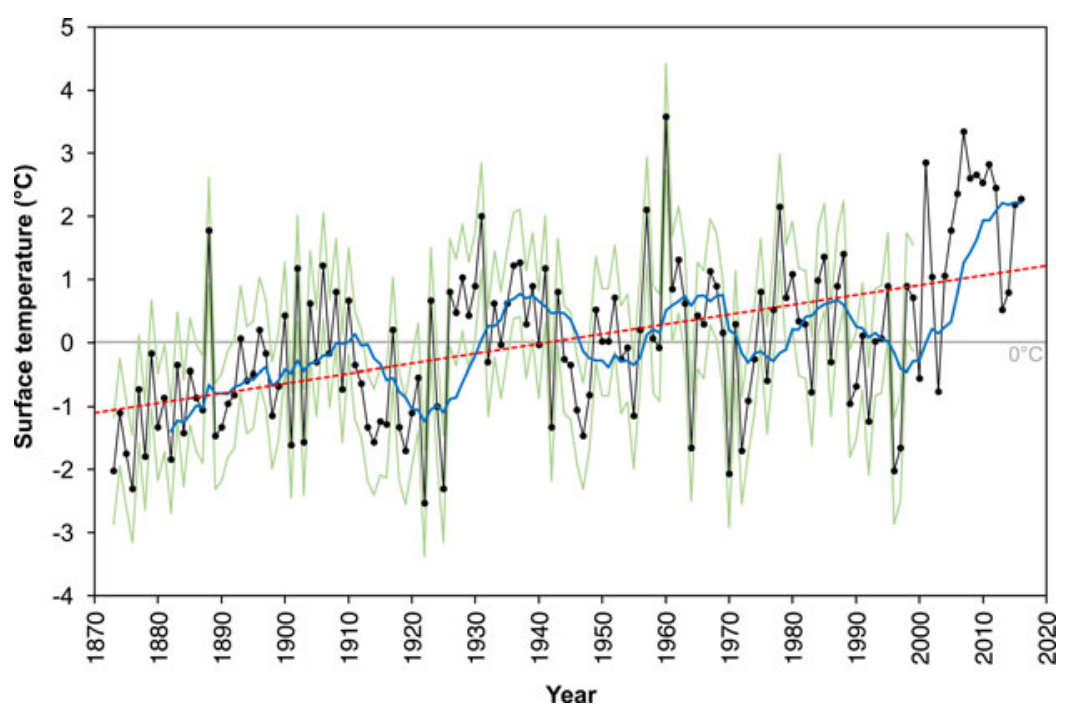

Fig. 5. Mean summer (July and August) surface-temperature anomalies (black line, with black circles showing individual yearly values) from 1873 to 2016 relative to the 20th-century baseline. Values from 1873 to 1999 are derived from AWS data (see the section 'Weather station temperature data'), while those in 2000-16 are derived from MODIS data (see the section 'MODIS temperature data'). The blue line shows the 10 -year moving average for surface-temperature anomalies. The green lines show the positive and negative error bounds for the weather station data in 1873-1999 (derived according to the section 'Weather station temperature data'); error bars are not shown for the 2000-16 MODIS data. The red dashed line is an OLS linear regression line $\left(y=0.0155 x-1.1182 ; r=0.505 ; R^{2}=0.255 ; p=0.000\right)$ to show the upward trend in surface-temperature anomalies over the period. The grey horizontal solid line shows the $0^{\circ} \mathrm{C}$ surface-temperature anomaly. 
Table 3. Mean summer (July and August) surface temperatures and surface-temperature anomalies in ${ }^{\circ} \mathrm{C}$ (relative to the 20th-century baseline value) for the years of data used in this study.

\begin{tabular}{lll}
\hline Year & Surface temperature $\left({ }^{\circ} \mathrm{C}\right)$ & $\begin{array}{l}\text { Surface-temperature } \\
\text { anomaly }\left({ }^{\circ} \mathrm{C}\right)\end{array}$ \\
\hline 1985 & -1.62 & +1.35 \\
1988 & -1.58 & +1.40 \\
1990 & -3.66 & -0.73 \\
1994 & -2.92 & +0.06 \\
2000 & -3.54 & -0.61 \\
2007 & 0.36 & +3.34 \\
2009 & -0.32 & +2.65 \\
2014 & -2.19 & +0.79 \\
2015 & -0.79 & +2.18 \\
2016 & -0.70 & +2.28 \\
\hline
\end{tabular}

was despite the mean elevation of SGLs being at its maximum (1164 $\mathrm{m}$ a.s.l.) during summer 2015, which had the second largest surface-temperature anomaly $\left(+2.18^{\circ} \mathrm{C}\right)$, and the 1990 and 2000 summers (with the most negative surface-temperature anomalies of -0.73 and $-0.61{ }^{\circ} \mathrm{C}$, respectively) showing lower mean SGL elevations of $946 \mathrm{~m}$ a.s.I. and $895 \mathrm{~m}$ a.s.I., respectively (Fig. 6b).

The influence of surface temperatures on SCL coverage The maximum regional areal extent of SGLs appeared to increase as the surface-temperature anomaly increased (Fig. 6c). For example, the maximum extent of SGLs in the summer with the most positive surface-temperature anomaly $\left(2016,+2.28^{\circ} \mathrm{C}\right)$ was $42.1 \%$ greater than the mean of the maximum areal extents of SGLs over the entire
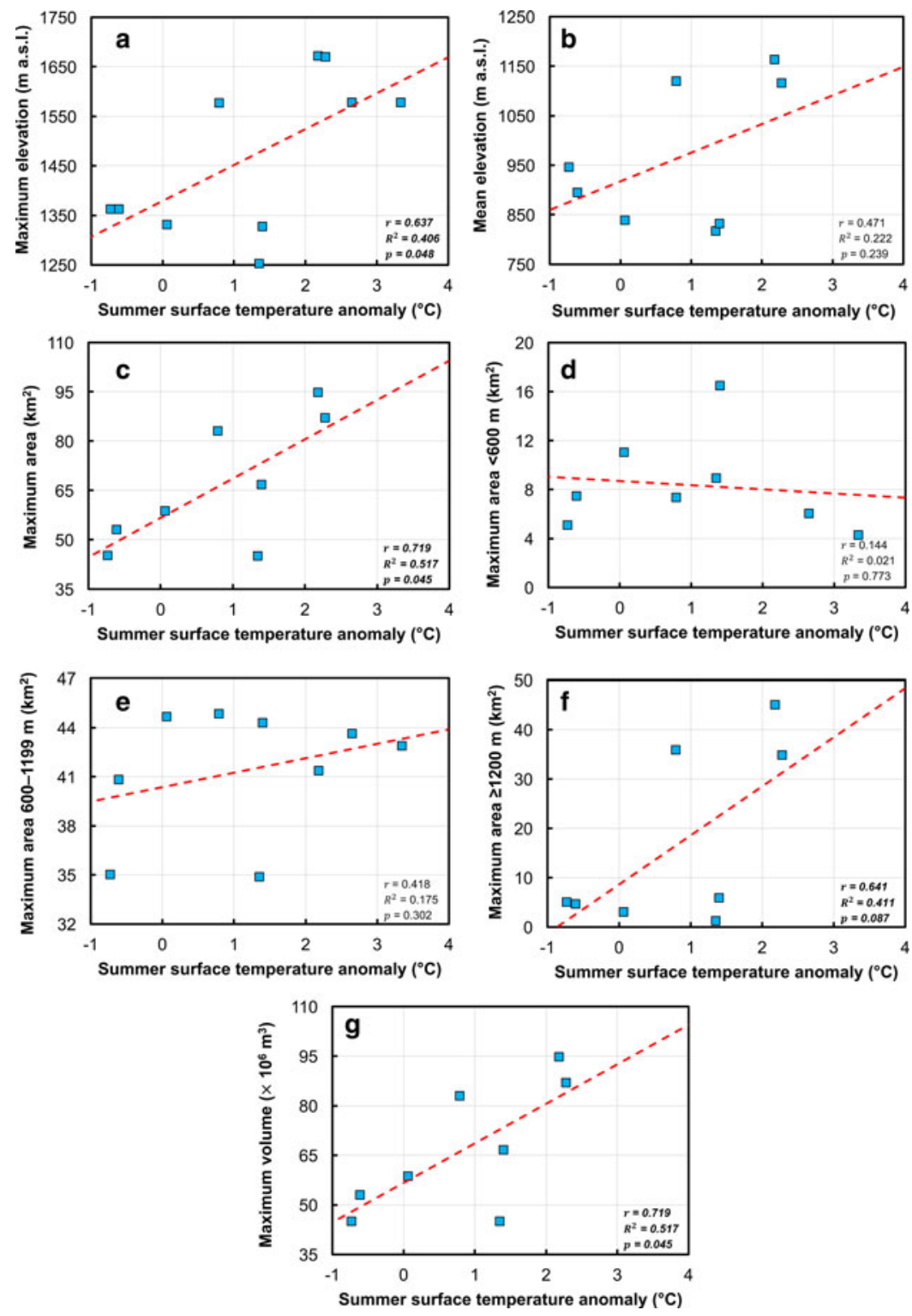

Fig. 6. The relationship between the summer (July and August) surface-temperature anomalies in 1985-2016 and (a) maximum SGL elevation, (b) area-weighted mean SGL elevation, (c) maximum areal SGL extent across the whole region, (d) maximum areal SGL extent at low surface elevations, (e) maximum areal SGL extent at medium surface elevations, ( $\mathrm{f}$ ) maximum areal SGL extent at high surface elevations, and (g) maximum volumetric SGL extent across the whole region. Red dashed lines show OLS linear regression lines. Significant $r$ values at above the $90 \%$ confidence interval $(p<0.1)$ are highlighted in bold italicised text on each panel. 
study period $\left(66.7 \mathrm{~km}^{2}\right)$. Similarly, the maximum areal extent of SGLs in the summer with the most negative surface-temperature anomaly $\left(1990,-0.73^{\circ} \mathrm{C}\right)$ was $32.2 \%$ smaller than the mean $\left(66.7 \mathrm{~km}^{2}\right)$ of the maximum areal extents over the study period. This pattern was confirmed by a moderatestrong positive correlation between maximum regional $\mathrm{SGL}$ area and the surface-temperature anomalies $(r=0.719$; $p=0.045)$, with the surface-temperature anomalies explaining $51.7 \%$ of the variance $\left(R^{2}=0.517, p=0.045\right)$ in the maximum areal extent of SGLs (Fig. 6c). Due to the linear SGL area-volume scaling relationship, the same correlation and regression relationships existed for the regional SGL volume data (Fig. 6g).

Despite this, we found no clear relationship between summer surface-temperature anomalies and the maximum areal extent of SGLs within the low and medium elevation bands. This was confirmed by linear correlation analysis, which indicated that the relationship between the areal extent of SGLs at low and medium elevations and surfacetemperature anomalies was not statistically significant: $r=0.144, p=0.733$ for low elevations, and $r=0.418$, $p=0.300$ for medium elevations, respectively (Figs 6d, e). By contrast, at high elevations, there was an apparent relationship between summer surface-temperature anomalies and the maximum areal extent of SGLs. Regression analysis confirmed the relationship between higher positive surfacetemperature anomalies and the greater areal extents of SGLs at high elevations $(r=0.641 ; p=0.087)$, with surface-temperature anomalies explaining $41.1 \%$ of the variance $\left(R^{2}=0.411, p=0.087\right)$ (Fig. 6f). During the summer with the highest positive surface-temperature anomaly $\left(2016,+2.28^{\circ} \mathrm{C}\right)$, the SGL area at $\geq 1200 \mathrm{~m}$ a.s.l. accounted for $40.1 \%\left(34.9 \mathrm{~km}^{2}\right)$ of the total SGL area $\left(87.1 \mathrm{~km}^{2}\right)$ across the region, nearly double the contribution of SGLs at these elevations $(21.0 \%)$ to the overall maximum extents during the entire 1985-2016 period. During the summer with the most negative surface-temperature anomaly (1990, $\left.-0.73^{\circ} \mathrm{C}\right)$, SGL area $\geq 1200 \mathrm{~m}$ a.s.l. only accounted for $11.1 \%\left(5.02 \mathrm{~km}^{2}\right)$ of total SGL area $\left(45.2 \mathrm{~km}^{2}\right)$, representing nearly half of the 1985-2016 mean value at these elevations derived from all of the maximum SGL extents.

\section{DISCUSSION}

\section{Increasing and accelerating regional surface temperatures}

Summer surface-temperature anomalies increased by $4.24^{\circ} \mathrm{C}$ in the study region from 1873 to 2016, with the most significant increases post-2000. This trend parallels that across the entire GrIS, which showed a similar $\left(\sim 1^{\circ} \mathrm{C}\right)$ albeit smaller warming trend over a comparable time period (1840-2007) (Box and others, 2009; Kobashi and others, 2011). The difference between the values in north-west Greenland and those for the entire GrlS adds validity to the assumptions of nonuniform patterns of temperature change thought to occur across the GrIS (Hall and others, 2008; Hanna and others, 2012; Cappelen and others, 2015). These findings indicate that studies modelling the GrlS's hydrology must account for this spatial unconformity in meteorological patterns, with attention given to ensuring that the past observations are reliably replicated by models before they are applied into the future.

\section{SGL migration to higher inland elevations}

The statistically significant increases to both the maximum and area-weighted mean elevations of SGLs over the study period (increases by $418 \mathrm{~m}$ and $299 \mathrm{~m}$, respectively) indicate a tendency for SGLs to form progressively further inland over the study period, with an acceleration post-2000 (Table 1 and Figs 2, 3a, b). This elevation increase is of the same order of magnitude as previous observations elsewhere in Greenland (Howat and others, 2013; Fitzpatrick and others, 2014), with Howat and others (2013) also noting an acceleration in 2000-12 compared with 1972-99. However, the annual rate of change to the maximum SGL elevation within our study region $\left(13.5 \mathrm{~m} \mathrm{a}^{-1}\right)$ was double the rate $\left(6.8 \mathrm{~m} \mathrm{a}^{-1}\right)$ within the adjacent basin in north-west Greenland studied by Howat and others (2013). This may be because the periods of study were different, since Howat and others (2013) only used data from before 2012, and there may have been notable increases since then. The rate we find is more akin to the rate $\left(16.5 \mathrm{~m} \mathrm{a}^{-1}\right)$ observed by Fitzpatrick and others (2014) for the Russell Glacier region of south-west Greenland, suggesting that there may be high variations in the rates of inland advance of SGLs across the GrlS. Since Howat and others' (2013) study also used primarily Landsat data, as well as other medium-resolution satellite datasets, the regional differences that we observe cannot be attributed to the inability of their study to identify small SGLs at these higher elevations, which would have been the case with Fitzpatrick and others' (2014) use of MODIS data.

\section{The influence of surface temperatures on SGL inland migration}

The migration of SGLs to higher maximum elevations appears to have been driven by the increases to summer surface temperatures, matching the findings of previous work (Liang and others, 2012; Fitzpatrick and others, 2014). Our analysis showed that surface temperature changes explained $\sim 40 \%$ of the variance in maximum SGL elevations (Fig. 6a), likely because higher surface temperatures promote increased surface melting across greater portions of the GrlS (Howat and others, 2013). Conversely, we found no relationship between surface-temperature anomalies and the area-weighted mean SGL elevation, showing that there is no tendency for SGLs to be present at higher mean elevations on the GrlS with increased temperatures (Fig. 6b). A possible explanation for this is that with higher surface temperatures, the statistically significant increases to the maximum SGL elevations are not so large that they bias the overall SGL elevation towards higher mean values. If imagery had been available from the extreme 2012 melt season (Noël and others, 2016), further conclusions could have been reached on the influence of surface temperatures on SGL inland migration, and particularly SGLs' response to such extreme values. Overall, Figure 6 shows that regional SGL characteristics cannot be inferred directly from surface temperature (and so surface melt intensity), indicating that there are likely to be other controls, such as the local glaciological characteristics (for example, the surface slope or the size of depressions) or hydrological characteristics (for example, the availability of meltwater or the patterns of its routing into lake basins) that control the evolution and morphology of SGLs within the study region. Furthermore, it is possible that using only surface temperatures, in the 
absence of other meteorological variables, cannot explain the observed variations, so if extra meteorological data had been included in the analysis, these may have been able to explain more of the observed interannual differences.

\section{Intra- and inter-ice-sheet sector variations in SGL inland} advance

Previous work has indicated that there is likely to be significant variations in the extent of inland migration of SGLs for different sectors of the GrIS (Howat and others, 2013; Leeson and others, 2015; Ignéczi and others, 2016). Our study also demonstrates that even within specific sectors of the GrlS (by comparing our results with those from the nearby basin studied by Howat and others (2013)), there may also be marked variation in the rate of inland SGL migration. The observed Greenland-wide variations in the patterns of the extent of inland SGL progression (Howat and others, 2013) are likely to be due to sector-specific variations in melt extent (Ohmura and Reeh, 1991; Abdalati and Steffen, 2001), topography (Ignéczi and others, 2016) and glacier dynamics (Rignot and Kanagaratnam, 2006). The results of this study therefore indicate that a similar set of controls may apply within ice-sheet sectors as well as between them. This agrees with recent work indicating that within ice-sheet sectors, there can be high variation in the number and size of ice-surface depressions, resulting from localscale variations in the controls on depression formation, such as basal sliding (Gudmundsson, 2003; Ignéczi and others, 2016). We therefore suggest that caution may be needed if applying the inferences of past and present SGL inland progression from one region of the GrIS to the entire GrIS (e.g. Leeson and others, 2015) and/or if assuming that the patterns of SGL change observed in one location on the GrIS will be necessarily representative of the entire GrIS. Instead, we recommend that finer-scale regional and sector-specific results for SGL migration should be ascertained first and then incorporated into models of the future progression of SGLs on the GrIS.

Finally, it appears that an upper altitudinal limit to SGL elevation within this study region has not yet been reached - indeed the rates of SGL migration to higher elevations were most notable during the latter part of the study period. This result agrees with Ignéczi and others (2016) who indicated that the upper limit to SGL formation in the region may be as high as $\sim 3000 \mathrm{~m}$ a.s.l. With a continually warming climate (Collins and others, 2013), and assuming a constant rate of SGL inland migration, it seems plausible that SGLs will form at higher surface elevations in the region in the future, although verification must be undertaken to determine whether the trend observed in the later part of our study period is likely to continue into the future. It is impossible with this study's results to speculate on whether these higher-elevation SGLs will be capable of hydrofracture in the future. However, our work suggests that since SGLs are forming at progressively higher elevations and covering greater extents at these elevations, with accelerations to these rates over time, further research should be directed towards determining whether these SGLs will be able to drain rapidly and, if they can, how this will implicate the GrlS's future dynamics. This research might build on existing observational (remote sensing or field) studies of rapid SGL drainage by including an examination of some of the potential drivers of the hydrofracture process, as well by furthering theoretical modelling work.

\section{Increases to the spatial coverage of SGLs}

Alongside the migration of SGLs to higher elevations, our findings show that the maximum areal and volumetric extent of SGLs significantly increased over the study period, nearly doubling between 1985 and 2016, with notable accelerations during the 21 st century. However, this trend was not uniform for all elevation bands, with the increases at low and medium elevations showing no statistically significant trend compared with the statistically significant increases at high elevations. The expansions to total SGL areas and volumes were therefore driven by changes at the highest elevations (as confirmed by multiple regression) rather than by changes for the entire ablation area. This result agrees with Sundal and others (2009) and Liang and others (2012) who showed that increases to SGL extent at high elevations drove recent changes to total regional SGL area and volume in their studies.

Given this finding, we investigated whether SGLs for the low, medium and high elevation bands showed significant changes to their mean and maximum sizes over the study period (Fig. 7). The aim here was to determine whether it is likely that even within the early part of the study period, low- and medium-elevation SGLs reached similar sizes to those at these elevations later in the period; if so, this might indicate a regional topographic control on their size,
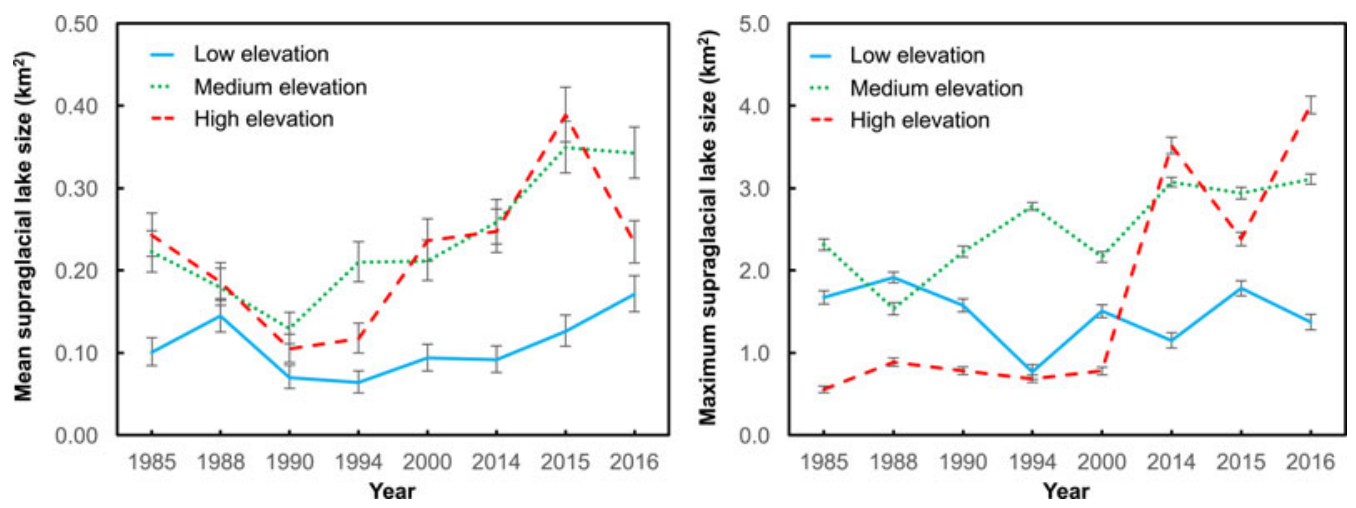

Fig. 7. Changes to SGL mean and maximum size over the study period divided into low ( $<600 \mathrm{~m}$ a.s.l; solid blue lines), medium (600-1199 $\mathrm{m}$ a.s.l.; dotted green lines) and high ( $\geq 1200 \mathrm{~m}$ a.s.l.; dashed red lines) elevation bands. Black error bars for SGL areas are derived according to methods in the section 'SGL delineation technique'. 
similar to that observed elsewhere, such as in the Paakitsoq and Store Glacier regions of West Greenland (Williamson and others, 2017). We found no statistically significant change to mean SGL size at low elevations $(r=0.405, p=$ 0.319 ) over the study period, suggesting that a regional control might prevent their growth to larger areas. By contrast, the mean SGL size significantly increased over the study period for SGLs at medium $(r=0.840, p=0.009)$ and high elevations $(r=0.617, p=0.010)$. A similar pattern also existed for the maximum SGL sizes: there were no statistically significant changes at low elevations $(r=$ $0.195, p=0.644)$, but significant increases were observed at medium $(r=0.794 ; p=0.019)$ and high elevations $(r=$ $0.899, p=0.002$ ).

These findings show that SGLs at the lowest $(<600 \mathrm{~m}$ a.s.l.) surface elevations remained approximately constant in size over the study period, indicating that during the earlier part of the study period, they might have already reached their maximum areas and could not grow larger later in the period. This probably indicates that the size of the depressions controlled their sizes, preventing the increased meltwater volumes during the later (post-2000) period from being accommodated within larger SGLs. While there may be small increases to SGL area and volume by enhanced SGL-bottom ablation (Lüthje and others, 2006; Tedesco and others, 2012), this shows that the bedrock topography and local sliding rates are a key control on SGL size (Thomsen and others, 1988; Echelmeyer and others, 1991; Gudmundsson, 2003; Lampkin and VanderBerg, 2011; Johansson and others, 2013). Consequently, statistically significant increases to the areas and volumes of these SGLs were impossible, so the increasing quantities of melt at low elevations during the later parts of the study period were presumably accommodated by the earlier drainage of SGLs, and the resultant opening of surface-to-bed connections, permitting the direct delivery of any future meltwater to the basal system for the remainder of the season (Colgan and others, 2011; Palmer and others, 2011; Banwell and others, 2013, 2016; Sole and others, 2013; Tedstone and others, 2014; Koziol and others, 2017). Meanwhile, in the earlier part of the study period, the basins at higher ( $\geq 600 \mathrm{~m}$ a.s.l.) elevations were likely to have been either empty or only partially filled, meaning that they were able to accommodate increasingly larger SGLs over the study period, shown by the increases to the mean and maximum sizes of SGLs at these elevations.

\section{The influence of surface temperatures on increased SGL coverage}

Our study shows that surface-temperature anomalies are a key driver of total SGL area and volume changes, being able to explain $>50 \%$ of the variance in total SGL area and volume (Figs 6c, g). This agrees with previous work showing that SGLs cover larger areas inland during warmer years (Sundal and others, 2009; Liang and others, 2012; Fitzpatrick and others, 2014). However, when we compared surface-temperature anomalies against total SGL areas at low, medium and high elevations, we found a significant correlation for only the high elevations (Figs $6 \mathrm{~d}-\mathrm{f}$ ). This is similar to the findings of Liang and others (2012), which showed that there was strong variation only for SGLs $>1050 \mathrm{~m}$ a.s.l. in response to melt intensity, and the results of Fitzpatrick and others (2014), which also showed that maximum SGL areal extent $>1400 \mathrm{~m}$ a.s.l. was strongly correlated with surfacetemperature anomalies in June and July.

Our results show that at low and medium elevations, when surface temperature increases, total SGL area does not increase. This might be because the higher melt with higher temperatures is accommodated not by growth to the area of SGLs at these elevations but instead is accommodated by the earlier rapid SGL drainage or by the overflow of individual SGLs to feed downglacier moulins/crevasses; this prevents the water within depressions from reaching the maximum size of the depressions. This agrees with Liang and others (2012) who found a significant correlation between mean SGL cessation date (due to rapid SGL drainage) and melt intensity, and between SGL duration (with a lower duration if SGLs drain rapidly) and melt intensity, indicating that SGLs drain earlier to compensate for increased meltwater volumes. It is also plausible that the prevalence, by comparison with higher elevations, of crevasses and moulins at low and medium surface elevations (Catania and others, 2008; Das and others, 2008; Colgan and others, 2011) allows the extra meltwater in high-temperature years to be routed directly to the bed instead of ponding supraglacially.

Contrastingly, at high elevations, the statistically significant correlation between surface-temperature anomalies and SGL area and volume indicates that extra melt can be accommodated by larger and/or more numerous SGLs. Given that there is such a strong correlation between the two variables, it is possible that: (i) high-elevation surface depression size does not (yet) control high-elevation SGL size; (ii) the lack of surface fractures compared with low and medium elevations means that surface water is stored within SGLs rather than being delivered directly to the bed; or (iii) high-elevation SGLs presently cannot drain rapidly by hydrofracture, meaning that with higher temperatures, total SGL area at these elevations instead continues to increase. The absence of rapid drainage may result from: (i) the lack of basal meltwater inputs to the subglacial drainage system elsewhere at high elevations (Stevens and others, 2015); (ii) the preclusion of rapid drainage due to the lack of surface crevasses at high elevations (Poinar and others, 2015); or (iii) the shallow ice-surface slopes at high elevations producing spatially expansive but shallow SGLs that cannot drain rapidly (Raymond and Nolan, 2000). The use of a more robust SGL area-volume scaling relationship, such as a physically-based one (Sneed and Hamilton, 2007), would allow the third possibility to be investigated more fully than is possible with the simple SGL area-volume linear relationship used here. Although this study could not examine whether rapid drainage at these elevations will be able to occur in the future, if hydrofracture could initiate, it is possible that with increased meltwater volumes associated with higher future temperatures (Collins and others, 2013), which appear to be accelerating, SGL area at high elevations would not be correlated so strongly with surface-temperature anomalies.

\section{Identification of small SGLS}

SGLs $<0.125 \mathrm{~km}^{2}$ in size (i.e. below MODIS's threshold reporting size) represented relatively high proportions of the regional SGL areal and volumetric extents. It is therefore evident that it is important to employ higher-resolution 
imagery to fully document past changes to SGL areas for different regions of the GrlS, meaning that studies based solely on MODIS (Sundal and others, 2009; Liang and others, 2012; Fitzpatrick and others, 2014) may have omitted some information on past changes to the GrIS's hydrology, particularly if calculating total regional areal and volumetric SGL extents. With the increasing availability of higher spatial and temporal resolution satellite imagery such as that derived from the Sentinel-2 satellite $(10 \mathrm{~m}$ spatial resolution and 4-day or better repeat times for Greenlandic latitudes), it will be possible to resolve much finer-scale changes to SGL metrics on the GrIS, including the identification of changes to supraglacial streams (Yang and Smith, 2013). Ultimately, this will provide a more valuable record of the GrIS's ongoing response to climatic warming than was possible for previous decades, such as those examined here.

\section{CONCLUSIONS}

The potential future expansion of SGLs to higher surface elevations on the GrlS, and particularly the possibility of their rapid drainage at these elevations, has received recent attention because of its implications for the GrlS's future mass balance if the subglacial system within the interior regions cannot evolve to higher hydraulic efficiency. Ultimately, this could produce longer-term, persistent ice speed-ups that may even offset the presently observed ice-velocity slowdowns closer to the ice margin. Towards eliciting the future locations and potential drainage locations of SGLs on the GrlS, and for determining the ongoing response of the GrlS's hydrology to climatic warming, some studies have examined changes to patterns of SGLs over the past decade (s). However, existing research was either temporally limited to post-2000 and used coarse-resolution MODIS data (Sundal and others, 2009; Liang and others, 2012; Fitzpatrick and others, 2014) or did not contextualise the observed changes to SGLs with surface temperature changes (Howat and others, 2013). Here, we addressed these shortfalls by conducting the longest-term (19852016) and highest spatial resolution $(30 \mathrm{~m})$ study of the past response of SGLs, examining not only changes to SGL elevations but also regional SGL areal and volumetric extents, then comparing the observations with surfacetemperature changes.

Our results showed that SGLs have advanced to higher maximum $(+418 \mathrm{~m})$ and mean $(+299 \mathrm{~m})$ elevations, with notable accelerations inland post-2000. In addition, the total regional SGL area and volume nearly doubled over the study period, again with large accelerations post-2000, which were driven by increases to the SGL area and volume at high ( $\geq 1200 \mathrm{~m}$ a.s.l.) surface elevations. Here, the maximum areal extent of SGLs increased by $>2750 \%$ over the study period and these high-elevation changes could explain $\sim 80 \%$ of the changes to the total regional SGL areal extent. The notable accelerations in the $21 \mathrm{st}$ century were mirrored by accelerations to surface temperatures (showing a two order of magnitude increase post2000 compared with beforehand). These temperature changes could explain the higher maximum SGL elevation, as well as the total SGL coverage across the region and at high elevations; however, we found no significant relation between SGL areas at low and medium elevations and the surface temperature changes. This is likely because depressions at the low and medium elevations control SGL size, whereas SGLs at higher elevations have not yet grown to fill the large depressions; it may also reflect the prevalence of moulins and crevasses at the lower elevations, meaning that increased meltwater here is routed directly to the bed instead of ponding within depressions as at the high elevations.

Collectively, our results are concerning since they show an accelerating and significant response of the GrIS's hydrological system to past climatic warming, which may result from anthropogenic climate change (Collins and others, 2013). With the apparent continued accelerating inland progression of SGLs over the most recent period, as well as the increasing SGL areas and volumes at high elevations, there is an urgent need to understand whether rapid SGL drainage by hydrofracture will be able to occur at these elevations and, if it can, how it will implicate ice dynamics in the future. Further work should focus on identifying whether the notable changes in the later part of this study (i.e. 2014-16) represent an ongoing trend to determine their relation to climate change. Our study also shows that there appears to be significant intra-ice-sheet variation in the response of SGLs to climatic warming, suggesting that finer spatial scale studies for different sectors of the GrlS would be merited. Finally, if it were possible to link the locations of SGLs and their drainage patterns over many years or decades to changes in the subglacial drainage system structure and the resultant ice velocities, much greater insights might be provided into the likely response of increasingly inland regions of the GrIS to SGL formation and potential SGL drainage in the future. This could enable improved confidence in the forecasts of ice-dynamic loss from the GrlS and consequently its potential contribution to global sea levels over the coming century.

\section{AUTHOR CONTRIBUTIONS}

Both authors contributed equally to this work. Under the supervision of AGW, LAG conceived the study, designed the research and undertook the majority of the data processing. Results and interpretation were discussed by both authors. AGW wrote the manuscript and created the figures based on LAG's undergraduate dissertation for Part II of the University of Cambridge Geographical Tripos. AGW responded to comments from reviewers and revised the manuscript.

\section{SUPPLEMENTARY MATERIAL}

The supplementary material for this article can be found at https://doi.org/10.1017/aog.2017.31.

\section{ACKNOWLEDGEMENTS}

LAG received a Hugh Brammer Vacation Study Grant (Downing College, Cambridge) to conduct the majority of the research. AGW was in receipt of a UK Natural Environment Research Council PhD studentship awarded through the Cambridge Earth System Science Doctoral Training Partnership (grant number: NE/L002507/1). We are grateful to James Kirkham for commenting on an early draft of the manuscript. We thank Gabriel Amable for providing technical assistance with certain aspects of the image processing and Mal McMillan for answering our questions on calculating the errors associated with manually digitising 
SGLs. We also acknowledge Poul Christoffersen's and Gareth Rees' preliminary suggestions during the study's conception. Finally, we thank two anonymous reviewers and the Scientific Editor, Allen Pope, for their thorough reviews that improved the manuscript.

\section{REFERENCES}

Abdalati W and Steffen K (2001) Greenland ice sheet melt extent: 1979-1999. J. Geophys. Res.: Atmos., 106(D24), 3398333988 (doi: 10.1029/2001JD900181)

Andrews LC and 7 others (2014) Direct observations of evolving subglacial drainage beneath the Greenland ice sheet. Nature, $\mathbf{5 1 4}$ (7520), 80-83 (doi: 10.1038/nature13796)

Arnold NS, Banwell AF and Willis IC (2014) High-resolution modelling of the seasonal evolution of surface water storage on the Greenland ice sheet. Cryosphere, 8(4), 1149-1160 (doi: 10.5194/tc-8-1149-2014)

Banwell AF, Willis IC and Arnold NS (2013) Modeling subglacial water routing at Paakitsoq, W Greenland. J. Geophys. Res.: Earth Surf., 118(3), 1282-1295 (doi: 10.1002/jgrf.20093)

Banwell AF and 5 others (2014) Supraglacial lakes on the Larsen B ice shelf, Antarctica, and at Paakitsoq, West Greenland: a comparative study. Ann. Glaciol., 55(66), 1-8 (doi: 10.3189/ 2014AoG66A049)

Banwell A, Hewitt I, Willis I and Arnold N (2016) Moulin density controls drainage development beneath the Greenland ice sheet. J. Geophys. Res.: Earth Surf., 121(12), 2248-2269 (doi: 10.1002/2015jf003801)

Bartholomew I and 5 others (2010) Seasonal evolution of subglacial drainage and acceleration in a Greenland outlet glacier. Nat. Geosci., 3(6), 408-411 (doi: 10.1038/ngeo863)

Bartholomew ID and 6 others (2011) Seasonal variations in Greenland ice sheet motion: inland extent and behaviour at higher elevations. Earth Planet. Sci. Lett., 307(3), 271-278 (doi: 10.1016/j.epsl.2011.04.014)

Box JE and Ski K (2007) Remote sounding of Greenland supraglacial melt lakes: implications for subglacial hydraulics. J. Glaciol., 53 (181), 257-265 (doi: 10.3189/172756507782202883)

Box JE, Yang L, Bromwich DH and Bai LS (2009) Greenland ice sheet surface air temperature variability: 1840-2007. J. Climate, 22(14), 4029-4049 (doi: 10.1175/2009JCLI2816.1)

Cappelen J, Vinther BM, Kern-Hansen C, Laursen EV and Jørgensen PV (2015) Technical report 15-04: Greenland - DMI historical climate data collection 1784-2014. Danish Meteorological Institute, Copenhagen

Catania GA, Neumann TA and Price SF (2008) Characterizing englacial drainage in the ablation zone of the Greenland ice sheet. J. Glaciol., 54(187), 567-578 (doi: 10.3189/002214 308786570854)

Chandler DM and 10 others (2013) Evolution of the subglacial drainage system beneath the Greenland ice sheet revealed by tracers. Nat. Geosci., 6(3), 195-198 (doi: 10.1038/ngeo1737)

Church JA and 13 others (2013) Sea level change. In Stocker TF and 9 others eds. Climate change 2013: the physical science basis. Contribution of working group I to the fifth assessment report of the intergovernmental panel on climate change. Cambridge University Press, Cambridge, UK and New York, NY, USA, 1137-1216 (doi: 10.1017/CBO9781107415324)

Colgan W and 7 others (2011) An increase in crevasse extent, West Greenland: hydrologic implications. Geophys. Res. Lett., 38, L18503 (doi: 10.1029/2011GL048491)

Collins M and 13 others (2013) Long-term climate change: projections, commitments and irreversibility. In Stocker TF and 9 others eds. Climate change 2013: the physical science basis. Contribution of working group I to the fifth assessment report of the intergovernmental panel on climate change. Cambridge University Press, Cambridge, UK and New York, NY, USA, 1029-1136 (doi: 10.1017/CBO9781107415324)
Cowton T and 7 others (2013) Evolution of drainage system morphology at a land-terminating Greenlandic outlet glacier. J. Geophys. Res.: Earth Surf., 118(1), 29-41 (doi: 10.1029/2012j f002540)

Das SB and 6 others (2008) Fracture propagation to the base of the Greenland ice sheet during supraglacial lake drainage. Science, 320(5877), 778-781 (doi: 10.1126/science.1153360)

Dow CF, Kulessa B, Rutt IC, Doyle SH and Hubbard A (2014) Upper bounds on subglacial channel development for interior regions of the Greenland ice sheet. J. Glaciol., 60(224), 1044-1052 (doi: 10.3189/2014JoG14J093)

Dow CF and 10 others (2015) Modeling of subglacial hydrological development following rapid supraglacial lake drainage. J. Geophys. Res.: Earth Surf., 120(6), 1127-1147 (doi: 10.1002/ 2014jf003333)

Doyle SH and 9 others (2013) Ice tectonic deformation during the rapid in situ drainage of a supraglacial lake on the Greenland ice sheet. Cryosphere, 7(1), 129-140 (doi: 10.5194/tc-7-129-2013)

Doyle SH and 6 others (2014) Persistent flow acceleration within the interior of the Greenland ice sheet. Geophys. Res. Lett., 41(3), 899-905 (doi: 10.1002/2013GL058933)

Echelmeyer K, Clarke TS and Harrison WD (1991) Surficial glaciology of Jakobshavns Isbræ, West Greenland: part I. Surface morphology. J. Glaciol., 37(127), 368-382 (doi: 10.1017/S0022 143000005803)

Enderlin EM and 5 others (2014) An improved mass budget for the Greenland ice sheet. Geophys. Res. Lett., 41(3), 866-872 (doi: 10.1002/2013GL059010)

Everett $A$ and 10 others (2016) Annual down-glacier drainage of lakes and water-filled crevasses at Helheim glacier, southeast Greenland. J. Geophys. Res.: Earth Surf., 121(10), 1819-1833 (doi: 10.1002/2016JF003831)

Fettweis X, Tedesco M, van den Broeke M and Ettema J (2011) Melting trends over the Greenland ice sheet (1958-2009) from spaceborne microwave data and regional climate models. Cryosphere, 5(2), 359-375 (doi: 10.5194/tc-5-359-2011)

Fettweis X and 5 others (2013) Brief communication: "Important role of the mid-tropospheric atmospheric circulation in the recent surface melt increase over the Greenland ice sheet". Cryosphere, 7(1), 241-248 (doi: 10.5194/tc-7-241-245013)

Fitzpatrick AAW and 9 others (2014) A decade (2002-2012) of supraglacial lake volume estimates across Russell glacier, west Greenland. Cryosphere, 8(1), 107-121 (doi: 10.5194/tc-8-1072014)

Georgiou S, Shepherd A, McMillan M and Nienow P (2009) Seasonal evolution of supraglacial lake volume from ASTER imagery. Ann. Glaciol., 50(52), 95-100 (doi: 10.3189/17275 6409789624328)

Gudmundsson GH (2003) Transmission of basal variability to a glacier surface. J. Geophys. Res.: Solid Earth, 108(B5), 2253 (doi: 10.1029/2002JB002107)

Hall DK, Williams RS, Luthcke SB and Digirolamo NE (2008) Greenland ice sheet surface temperature, melt and mass loss: 2000-06. J. Glaciol., 54(184), 81-93 (doi: 10.3189/002214 308784409170)

Hanna E and 8 others (2008) Increased runoff from melt from the Greenland ice sheet: a response to global warming. J. Climate, 21(2), 331-341 (doi: 10.1175/2007JCLI1964.1)

Hanna E, Mernild SH, Cappelen J and Steffen K (2012) Recent warming in Greenland in a long-term instrumental (18812012) climatic context: I. Evaluation of surface air temperature records. Environ. Res. Lett., 7(4), 045404 (doi: 10.1088/17489326/7/4/045404)

Helm V, Humbert A and Miller H (2014) Elevation and elevation change of Greenland and Antarctica derived from CryoSat-2. Cryosphere, 8(4), 1539-1559 (doi: 10.5194/tc-8-1539-2014)

Hoffman MJ, Catania GA, Neumann TA, Andrews LC and Rumrill JA (2011) Links between acceleration, melting, and supraglacial lake drainage of the western Greenland ice sheet. J. Geophys. Res.: Earth Surf., 116(F4) (doi: 10.1029/2010JF001934) 
Howat IM, de la Peña S, van Angelen JH, Lenaerts TM and van den Broeke MR (2013) Brief communication: "Expansion of meltwater lakes on the Greenland ice sheet". Cryosphere, 7(1), 201-204 (doi: 10.5194/tc-7-201-2013)

Howat IM, Negrete A and Smith BE (2014) The Greenland ice mapping project (GIMP) land classification and surface elevation data sets. Cryosphere, 8(4), 1509-1518 (doi: 10.5194/tc-8-15092014)

Ignéczi A and 7 others (2016) Northeast sector of the Greenland ice sheet to undergo the greatest inland expansion of supraglacial lakes during the 21st century. Geophys. Res. Lett., 43(18), 9729-9738 (doi: 10.1002/2016GL070338)

Johansson AM and Brown IA (2013) Adaptive classification of supraglacial lakes on the west Greenland ice sheet. IEEE J. Sel. Topics. Appl. Earth Observ. in Remote Sens., 6(4), 1998-2007 (doi: 10.1109/ISTARS.2012.2233722)

Johansson AM, Jansson P and Brown IA (2013) Spatial and temporal variations in lakes on the Greenland ice sheet. J. Hydrol., 476, 314-320 (doi: 10.1016/j.jhydrol.2012.10.045)

Joughin I and 5 others (2008) Seasonal speedup along the western flank of the Greenland ice sheet. Science, 320(5877), 781-783 (doi: 10.1126/science.1153288)

Kobashi T and 7 others (2011) High variability of Greenland surface temperature over the past 4000 years estimated from trapped air in an ice core. Geophys. Res. Lett., 38(21) (doi: 10.1029/2011 GL049444)

Koziol C, Arnold N, Pope A and Colgan W (2017) Quantifying supraglacial meltwater pathways in the Paakitsoq region, West Greenland. J. Glaciol., 63(239), 464-476 (doi: 10.1017/jog. 2017.5)

Krabill W and 12 others (2004) Greenland ice sheet: increased coastal thinning. Geophys. Res. Lett., 31(24) (doi: 10.1029/ 2004GL021533)

Krawczynski MJ, Behn MD, Das SB and Joughin I (2009) Constraints on the lake volume required for hydro-fracture through ice sheets. Geophys. Res. Lett., 36(10) (doi: 10.1029/2008G L036765)

Lampkin DJ (2011) Supraglacial lake spatial structure in western Greenland during the 2007 ablation season. J. Geophys. Res.: Earth Surf., 116(F4) (doi: 10.1029/2010JF001725)

Lampkin DJ and VanderBerg J (2011) A preliminary investigation of the influence of basal and surface topography on supraglacial lake distribution near Jakobshavn Isbrae, western Greenland. Hydrol. Process., 25(21), 3347-3355 (doi: 10.1002/hyp.8170)

Langley ES, Leeson AA, Stokes CR and Jamieson SS (2016) Seasonal evolution of supraglacial lakes on an East Antarctic outlet glacier. Geophys. Res. Lett., 43(16), 8563-8571 (doi: 10.1002/2016G L069511)

Leeson AA and 7 others (2013) A comparison of supraglacial lake observations derived from MODIS imagery at the western margin of the Greenland ice sheet. J. Glaciol., 59(218), 11791188 (doi: 10.3189/2013JoG13J064)

Leeson AA and 6 others (2015) Supraglacial lakes on the Greenland ice sheet advance inland under warming climate. Nat. Clim. Change, 5(1), 51-55 (doi: 10.1038/nclimate2463)

Liang Y and 7 others (2012) A decadal investigation of supraglacial lakes in West Greenland using a fully automatic detection and tracking algorithm. Remote Sens. Environ., 123, 127-138 (doi: 10.1016/j.rse.2012.03.020)

Lüthje M, Pedersen LT, Reeh N and Greuell W (2006) Modelling the evolution of supraglacial lakes on the West Greenland ice-sheet margin. J. Glaciol., 52(179), 608-618 (doi: 10.3189/17275 6506781828386)

Mayaud JR, Banwell AF, Arnold NS and Willis IC (2014) Modeling the response of subglacial drainage at Paakitsoq, west Greenland, to 21 st century climate change. J. Geophys. Res.: Earth Surf., 119, 2619-2634 (doi: 10.1002/2014JF003271)

McMillan M, Nienow P, Shepherd A, Benham T and Sole A (2007) Seasonal evolution of supra-glacial lakes on the Greenland ice sheet. Earth Planet. Sci. Lett., 262(3), 484-492 (doi: 10.1016/j. epsl.2007.08.002)

McMillan M and 14 others (2016) A high-resolution record of Greenland mass balance. Geophys. Res. Lett., 43(13), 70027010 (doi: 10.1002/2016GL069666)

Meierbachtol T, Harper J and Humphrey N (2013) Basal drainage system response to increasing surface melt on the Greenland ice sheet. Science, 341(6147), 777-779 (doi: 10.1126/science. 1235905)

Miles KE, Willis IC, Benedek CL, Williamson AG and Tedesco M (2017) Toward monitoring surface and subsurface lakes on the Greenland ice sheet using sentinel-1 SAR and landsat-8 OLI imagery. Front. Earth Sci., 5(58), 1-17 (doi: 10.3389/feart.2017. 00058)

Moon T and 6 others (2014) Distinct patterns of seasonal Greenland glacier velocity. Geophys. Res. Lett., 41(20), 7209-7216 (doi: 10.1002/2014GL061836)

Morriss BF and 7 others (2013) A ten-year record of supraglacial lake evolution and rapid drainage in West Greenland using an automated processing algorithm for multispectral imagery. Cryosphere, 7(6), 1869-1877 (doi: 10.5194/tc-7-1869-2013)

Moussavi MS and 6 others (2016) Derivation and validation of supraglacial lake volumes on the Greenland ice sheet from high-resolution satellite imagery. Remote Sens. Environ., 183, 294-303 (doi: 10.1016/j.rse.2016.05.024)

Noël B and 6 others (2016) A daily, 1-km resolution data set of downscaled Greenland ice sheet mass balance (1958-2015). Cryosphere, 10, 2361-2377 (doi: 10.5194/tc-10-2361-2016)

Ohmura A and Reeh N (1991) New precipitation and accumulation maps for Greenland. J. Glaciol., 37(125), 140-148 (doi: 10.1017/ S0022143000042891)

Palmer S, Shepherd A, Nienow P and Joughin I (2011) Seasonal speedup of the Greenland ice sheet linked to routing of surface water. Earth Planet. Sci. Lett., 302, 423-428 (doi: 10.1016/j. epsl.2010.12.037)

Phillips T, Rajaram H and Steffen K (2010) Cryo-hydrologic warming: a potential mechanism for rapid thermal response of ice sheets. Geophys. Res. Lett., 37(20) (doi: 10.1029/2010G L044397)

Phillips T, Rajaram H, Colgan W, Steffen K and Abdalati W (2013) Evaluation of cryo-hydrologic warming as an explanation for increased ice velocities in the wet snow zone, Sermeq Avannarleq, West Greenland. J. Geophys. Res.: Earth Surf., 118 (3), 1241-1256 (doi: 10.1002/jgrf.20079)

Poinar K and 5 others (2015) Limits to future expansion of surfacemelt-enhanced ice flow into the interior of western Greenland. Geophys. Res. Lett., 42(6), 1800-1807 (doi: 10.1002/2015G L063192)

Pope A (2016) Reproducibly estimating and evaluating supraglacial lake depth with Landsat 8 and other multispectral sensors. Earth Space Sci., 3, 176-188 (doi: 10.1002/2015EA000125)

Pope A and 6 others (2016) Estimating supraglacial lake depth in West Greenland using Landsat 8 and comparison with other multispectral methods. Cryosphere, 10, 15-27 (doi: 10.5194/ tc-10-15-2016)

Pritchard HD, Arthern RJ, Vaughan DG and Edwards LA (2009) Extensive dynamic thinning on the margins of the Greenland and Antarctic ice sheets. Nature, 461(7266), 971-975 (doi: 10.1038/nature08471)

Raymond CF and Nolan M (2000) Drainage of a glacial lake through an ice spillway. IAHS Publ., 264, 199-210

Rignot $\mathrm{E}$ and Kanagaratnam P (2006) Changes in the velocity structure of the Greenland ice sheet. Science, 311(5763), 986-990 (doi: 10.1126/science.1121381)

Schoof C (2010) Ice-sheet acceleration driven by melt supply variability. Nature, 468(7325), 803-806 (doi: 10.1038/nature09618)

Selmes N, Murray T and James TD (2011) Fast draining lakes on the Greenland ice sheet. Geophys. Res. Lett., 38(15) (doi: 10.1029/ 2011GL047872) 
Selmes N, Murray T and James TD (2013) Characterizing supraglacial lake drainage and freezing on the Greenland ice sheet. Cryos. Discuss., 7(1), 475-505 (doi: 10.5194/tcd-7475-2013)

Shepherd A and 5 others (2009) Greenland ice sheet motion coupled with daily melting in late summer. Geophys. Res. Lett., 36(1) (doi: 10.1029/2008GL035758)

Sneed WA and Hamilton GS (2007) Evolution of melt pond volume on the surface of the Greenland ice sheet. Geophys. Res. Lett., 34 (3) (doi: 10.1029/2006GL028697)

Sole A and 6 others (2013) Winter motion mediates dynamic response of the Greenland ice sheet to warmer summers. Geophys. Res. Lett., 40(15), 3940-3944 (doi: 10.1002/grl.50764)

Stevens LA and 7 others (2015) Greenland supraglacial lake drainages triggered by hydrologically induced basal slip. Nature, 522(7554), 73-76 (doi: 10.1038/nature14608)

Sundal AV and 5 others (2009) Evolution of supra-glacial lakes across the Greenland ice sheet. Remote Sens. Environ., 113 (10), 2164-2171 (doi: 10.1016/j.rse.2009.05.018)

Sundal AV and 5 others (2011) Melt-induced speed-up of Greenland ice sheet offset by efficient subglacial drainage. Nature, 469 (7331), 521-524 (doi: 10.1038/nature09740)

Tedesco M and 7 others (2012) Measurement and modeling of ablation of the bottom of supraglacial lakes in western Greenland. Geophys. Res. Lett., 39(2), L02052 (doi: 10.1029/ 2011GL049882)

Tedesco $M$ and 5 others (2013) Ice dynamic response to two modes of surface lake drainage on the Greenland ice sheet. Environ. Res. Lett., 8(3), 034007 (doi: 10.1088/1748-9326/8/3/034007)

Tedstone AJ, Nienow PW, Gourmelen N and Sole AJ (2014) Greenland ice sheet annual motion insensitive to spatial variations in subglacial hydraulic structure. Geophys. Res. Lett., 41 (24), 8910-8917 (doi: 10.1002/2014GL062386)

Tedstone AJ and 5 others (2015) Decadal slowdown of a land-terminating sector of the Greenland ice sheet despite warming. Nature, 526(7575), 692-695 (doi: 10.1038/nature15722)

Thomsen HH, Thorning L and Braithwaite RJ (1988) Glacier-hydrological conditions on the Inland Ice north-east of Jakobshavn/ Ilulissat, West Greenland: 1:75 000 scale map with explanation on reverse side. Rapport Grønlands Geologiske Undersøgelse, 138

van de Wal RS and 6 others (2008) Large and rapid melt-induced velocity changes in the ablation zone of the Greenland ice sheet. Science, 321(5885), 111-113 (doi: 10.1126/science. 1158540)

van de Wal RS and 10 others (2015) Self-regulation of ice flow varies across the ablation area in south-west Greenland. Cryosphere, 9 (2), 603-611 (doi: 10.5194/tc-9-603-2015)

Vaughan DG and 13 others (2013) Observations: cryosphere. In Stocker TF and 9 others eds. Climate change 2013: the physical science basis. Contribution of working group I to the fifth assessment report of the intergovernmental panel on climate change. Cambridge University Press, Cambridge, UK and New York, NY, USA, 317-382 (doi: 10.1017/CBO9781107415324)

Weisberg S (2005) Applied linear regression, 3rd edn. John Wiley and Sons, Hoboken (doi: 10.1002/0471704091)

Williamson AG, Arnold NS, Banwell AF and Willis IC (2017) A fully automated supraglacial lake area and volume tracking ("FAST") algorithm: development and application using MODIS imagery of West Greenland. Remote Sens. Environ., 196, 113-133 (doi: 10.1016/j.rse.2017.04.032)

Yang K and Smith LC (2013) Supraglacial streams on the Greenland ice sheet delineated from combined spectral-shape information in high-resolution satellite imagery. IEEE Geosci. Remote Sens. Lett., 10(4), 801-805 (doi: 10.1109/LGRS.2012.2224316)

Yang K, Smith LC, Chu VW, Gleason CJ and Li M (2015) A caution on the use of surface digital elevation models to simulate supraglacial hydrology of the Greenland ice sheet. IEEE J. Sel. Topics. Appl. Earth Observ. in Remote Sens., 8(11), 5212-5224 (doi: 10.1109/JSTARS.2015.2483483)

Zwally HJ and 7 others (2005) Mass changes of the Greenland and Antarctic ice sheets and shelves and contributions to sea-level rise: 1992-2002. J. Glaciol., 51(175), 509-527 (doi: 10.3189/ 172756505781829007)

Zwally HJ and 11 others (2011) Greenland ice sheet mass balance: distribution of increased mass loss with climate warming; 200307 versus 1992-2002. J. Glaciol., 57(201), 88-102 (doi: 10.3189/ 002214311795306682 